\title{
A DIGITAL TWIN USES CLASSIFICATION SYSTEM FOR URBAN PLANNING \& CITY INFRASTRUCTURE MANAGEMENT
}

\author{
SUBMITTED: March 2021
}

REVISED: August 2021

PUBLISHED: November 2021

GUEST EDITORS: Nashwan Dawood, Farzad Pour Rahimian

DOI: $10.36680 /$ j.itcon.2021.045

\author{
Ramy Al-Sehrawy \\ Department of Architecture \& Built Environment, Northumbria University; \\ ramy.alsehrawy@northumbria.ac.uk \\ Bimal Kumar \\ Department of Architecture \& Built Environment, Northumbria University; \\ bimal.kumar@northumbria.ac.uk \\ Richard Watson \\ Department of Architecture \& Built Environment, Northumbria University; \\ richard.watson@northumbria.ac.uk
}

SUMMARY: Recently, the concept of Digital Twin [DT] has pervaded the field of urban planning and city infrastructure management. This paper first affirms that the knowledge created by virtue of DT real-world implementation, through undertaking various DT pilot projects, case studies and proof-of-concept initiatives, comprises the 'know-how' and genuine practical experience upon which the DT research and practices can further develop and mature. It then argues that this type of knowledge is poorly captured and mostly left neither realized nor fully utilized. This significantly hinders the rate by which DT practices within the urban and built environments evolve. While acknowledging the benefits of the ongoing work by many DT researchers, including enumeration, categorization and detailing of multiple DT use cases, such endeavours arguably suffer from three profound weaknesses causing the inefficient sharing and transfer of DT 'know-how' knowledge amongst DT stakeholders. The three limitations are: (a) lack of DT standard terminology constituting a common DT language; (b) lack of standard and clear methods to enable documenting DT projects and making the 'know-how' explicit to the rest of the DT market; and (c) the lack of an established and adequate DT use cases classifications system to guide DT practitioners in searching for and retrieving the previously accomplished DT case studies that are most relevant to their interests and context. Correspondingly, three solutions are proposed constituting a three-pronged DT Uses Classification System [DTUCS]: prong-A (i.e. Standardize-to-Publish); prong-B (i.e. Detail-to-Prove); and prong-C (i.e. Classify-to-Reach). DTUCS is developed using a meta-methodology encapsulating a systematic literature review and three distinct sub-methodologies. The paper concludes with an overview of the implications of DTUCS along with recommendations on how it can be further validated and improved.

KEYWORDS: Urban, Digital Twin (DT), Use-case, knowledge transfer, standards

REFERENCE: Ramy Al-Sehrawy, Bimal Kumar, Richard Watson (2021). A digital twin uses classification system for urban planning \& city infrastructure management. Journal of Information Technology in Construction (ITcon), Special issue: 'Construction 4.0: Established and Emerging Digital Technologies within the Construction Industry (ConVR 2020)', Vol. 26, pg. 832-862, DOI: 10.36680/j.itcon.2021.045

COPYRIGHT: (C) 2021 The author(s). This is an open access article distributed under the terms of the Creative Commons Attribution 4.0 International (https://creativecommons.org/licenses/by/4.0/), which permits unrestricted use, distribution, and reproduction in any medium, provided the original work is properly cited. 


\section{INTRODUCTION}

The evolving concept of 'Digital Twin' [DT] has been recently gaining ground in the realms of urban planning and city infrastructure management. So far, no real consensus has emerged within these fields with regard to its definition. Concluding a multidisciplinary review of how DT is conceptualized across several sectors, Al-Sehrawy and Kumar (2021, p.926) described a DT as "the concept of connecting a physical system to its virtual representation via bidirectional communication (with or without human in the loop)... [allowing] for exploitation of Artificial Intelligence and Big Data Analytics... to unlock value". Accordingly, in a broader sense, a DT for urban planners and city infrastructure managers is primarily about leveraging urban data to support decision making with the aid of new-generation IT tools.

DT pilot projects, proof-of-concepts and case studies are proliferating \& various DT researchers are working on highlighting, grouping and categorize the various DT use cases (Brilakis et al., 2019; IET, 2019; DTHub, 2020; Al-Sehrawy \& Kumar, 2021; National Digital Twin Programme, 2021). Such endeavours support the idea of a DT to gradually mature, demonstrate the value and potential of DT and help getting buy-in from the key stakeholders and decision makers within urban and built environments (National Digital Twin Programme, 2021).

However, the knowledge created through these DT projects, comprising the 'know-how', practical experience gained and lessons learnt by virtue of real-world DT implementation, we argue, is improperly captured and largely left unrealized and not fully utilized. This consequently hinders the rate by which DT practices develop and DT market evolves.

This problem is caused by three distinct reasons. First is the lack of a standard language and terminology for DT stakeholders to consistently and comprehensively communicate, share and transfer DT-related knowledge without any confusion or ambiguity. Secondly, there appears to be no standard and robust method that DT researchers and practitioners can use to document the DT projects carried out in a detailed yet easy to understand form. If such a method had existed, the 'know-how' and the practical knowledge concerned with a particular DT could be made explicit for all interested parties across the DT market to re-utilize. Thirdly, amid the exponential increase in the number of DT projects and studies taking place, it is becoming increasingly challenging for DT developers to search for and retrieve information about completed DT projects relevant to the DT use case of interest. This draws the attention to the need for a more sophisticated search engine to help DT developers and practitioners to discover the "know-how" relevant to their particular DT projects or applications.

Hence, the purpose of this paper is to develop a Digital Twin Uses Classification System [DTUCS]. It is a holistic multi-purpose framework comprising three prongs to tackle the three issues identified above. These are: (a) standardizing the terminology used by DT stakeholders to communicate across the DT market to avoid any confusion or ambiguities; (b) enabling detailed documentation of DT-user interactions (i.e. the sequence of actions that should be undertaken by DT and its users through-out the developing and implementation of a DT) in a standard depictable format. This uncovers the 'know-how' and generates a tangible, explicit and easy-to-interpret form of the practical knowledge pertaining to a DT. Consequently, this may offer guidance to DT practitioners and a proof of achievability or buildability of any DT use case to concerned DT owners; and (c) classifying any DT use case via a multi-dimensional classification system to better define and specify any DT use case at the outset or after the DT implementation. This facilitates DT developers to search for and retrieve DT use cases of relevance to their interests based on the classification criteria or dimensions.

\section{DTUCS - WHY \& HOW}

\subsection{Publish it}

Table 1 below introduces 3 key terms fundamental to this paper. While a General Use Case (GUC) (table 1) identifies a particular DT purpose, a Use Case Scenario (UCS) documents the practical specificities and details of DT development and implementation, and validates or refutes the untested assumptions posited by the suggested GUC. The practical knowledge (i.e. know-how) gained through carrying out a UCS (table 1) must be communicated in a standard, common language if it is to be effectively transferred, made public or applied in a different context. A UCS described in an ad-hoc manner or in a localised technical language only known to the authors and alien to other DT stakeholders is more likely to be misinterpreted by the latter. Hence, standardizing the terminology adopted by DT stakeholders is key to successful dissemination of gained experiences and practical knowledge. To accomplish this, the notion of 'DT uses' (table 1) is proposed. DT uses are the standard building 
blocks used to document a UCS. They constitute a DT standard 'vocabulary' of functions, actions or techniques that are the basis of a standard common language for documenting and communicating DT Use Case Scenarios.

Table 1. Definition of key terms

\begin{tabular}{|l|l|}
\hline Key term & Definition \\
\hline DT General Use Case [GUC] & $\begin{array}{l}\text { The ultimate purpose motivating the use of a DT. A very short sentence, possibly consisting of two or } \\
\text { three words - ideally a verb followed by a noun - ultimately concerned with the brief and precise statement } \\
\text { of the central business aim that is motivating the use and implementation of a DT. e.g., 'optimize traffic'. }\end{array}$ \\
\hline DT Use Case Scenario [UCS] & $\begin{array}{l}\text { A documented scenario comprising the sequence of DT-user interactions executed through a particular } \\
\text { DT in support of a GUC. }\end{array}$ \\
\hline DT Use & A typical technical function, action or technique executed by a DT throughout the course of a UCS. \\
\hline
\end{tabular}

\subsection{Prove it}

Obviously, a mere statement of a GUC (e.g. optimize traffic) provides no solid basis to determine the capability of a particular DT (e.g. the ability to optimize traffic). In that sense, knowledge about how a DT may actually deliver the stated GUC must be made explicit to demonstrate how this GUC can actually be delivered. One method of achieving this is to articulate the sequence of actions undertaken and validated to complete a UCS carried out to yield the promised objective of the GUC. The "know-how" of the UCS (e.g. how a particular DT built to optimize traffic has been developed and put into action to attain its goal) should be documented in a recipe-like form in order to prove to the wider DT market, stakeholders and asset owners that the associated GUC is in fact achievable, reproducible and worthy of the investment. Not surprisingly, this task of documenting UCSs can hugely benefit from the standard terminology and the one common language, argued for in section 2.1. Moreover, standard terminology supported by a standard machine-readable language (e.g. UML) may pave the way for automating the detailing and documentation of UCS.

\subsection{Classify it}

Now, we have laid the foundations for capturing the know-how created while implementing UCSs, using standard terminology, a common language and means for documenting the details of the UCS. However, a vital issue may still hinder the transfer and re-use of this collected explicit knowledge: stakeholders need to be able to find it.

Undoubtedly, the pace at which the DT market develops, DT research progresses and UCSs proliferate has recently been increasing considerably. Similarly, the future rate of discovering new GUCs, as the DT market develops, is anticipated to grow exponentially (Broo et al., 2020). This is also prompted by the support of a national programme aiming to create a National Digital Twin [NDT] for UK (National Infrastructure Commission, 2017), supported by Centre for Digital Built Britain [CDBB]. Accordingly, a crucial question arising from such a situation is: 'how will it be feasible or even possible for DT owners, researchers or practitioners to filter and retrieve from a giant pool of published UCSs only those which are deemed most relevant to their research question or problem situation?!' Unless we address this question, we risk a great deal of the shared 'know-how' and value being lost in the digital space, hindering the effective development of future DTs that could build on this knowledge.

A standard DT use cases classification framework can enhance accessibility of relevant GUCs and UCSs and enable the efficient searching for them. DT literature and research has proposed numerous ways of thematizing or classifying the GUCs. Typically, DT researchers observe the DT pilot projects, proof-of-concepts and empirical studies undertaken so far to understand what DTs are currently being used for. Some may then enumerate DT use cases, purposes or ultimate goals of application (Fig. 1 - a). Others refer to three management levels that DT can contribute to (i.e. strategic, tactical and operational) (Xie et al., 2018). Another framework allocates DT use cases to one of three temporal-scale groups: long-term; short-term or real-time and near-real-time (Bibri, 2018b). Fig. 1 - b illustrates a framework consisting of four distinct areas that Brilakis et al. (2019) see as the most significant areas of DT application. In a workshop led by the CDBB's Digital Twin Hub (DTHub, 2020), participants first enumerated 28 different DT GUCs, then grouped the identified use cases in a three-themed framework reflecting the three pillars of sustainability: social, economic and environmental (Fig. $1-\mathrm{c}$ ). In the same sense, Fig. $1-\mathrm{d}$ illustrates the DT use cases framework developed by National Digital Twin Programme (2021) encompassing three groups, each representing a distinct DT purpose or area of application. 
The diversity of these frameworks reflects the broad and far-reaching potential of DTs. As well as lacking consistency and comprehensibility, all these frameworks or use case classification systems are limited and inadequate when it comes to searching for published UCSs relevant to a particular application at focus. This is because all fail in capturing the various DT features and characteristics neither comprehensively nor to an adequate

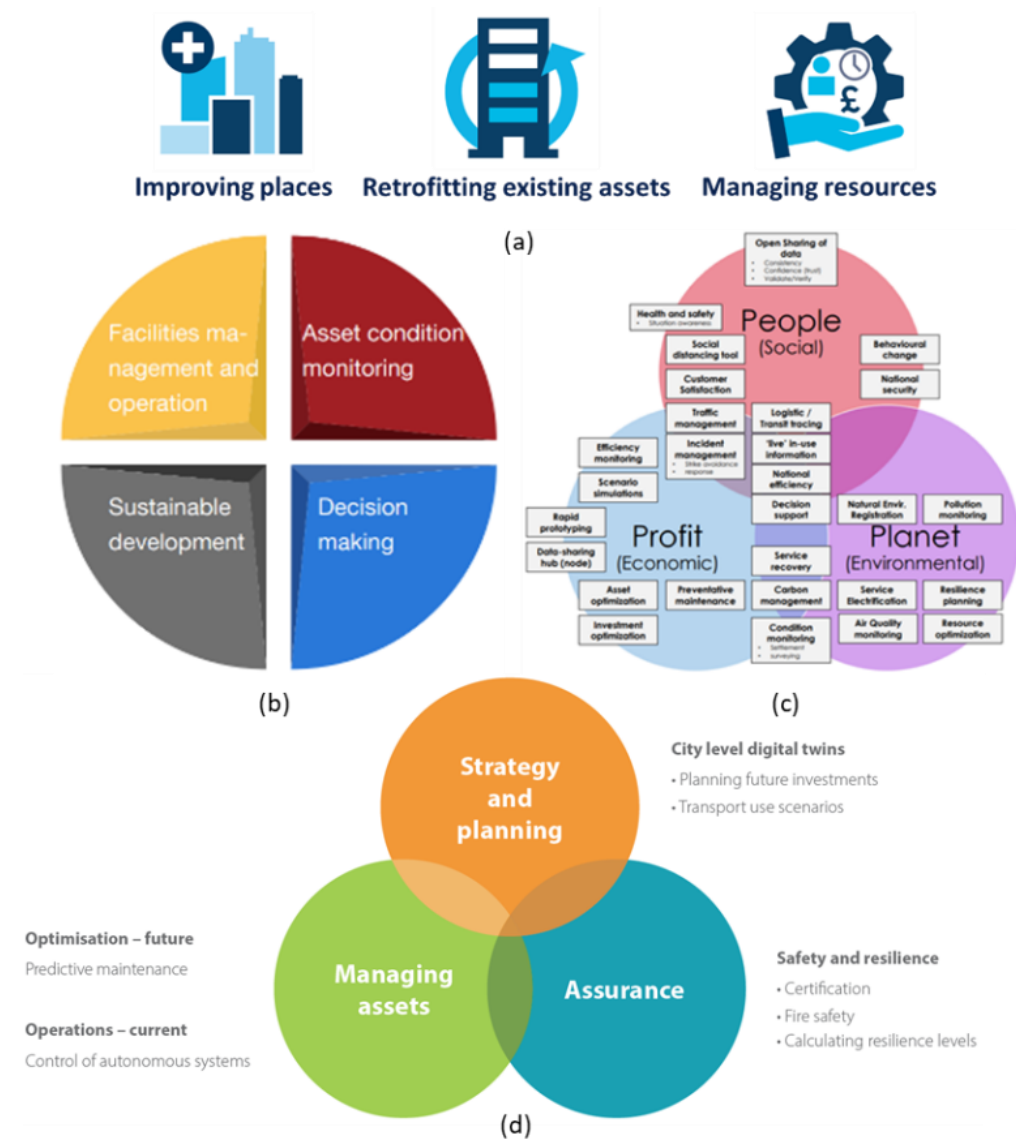

level of detail to support effective searching in terms of relevance and manageability of UCSs retrieved.

FIG. 1: Mainstream approach to get buy-in for DT: (a) enumerated DT use-cases or purposes (IET, 2019); (b) unidimensional framework (Brilakis et al., 2019); (c) enumerated DT use-cases imposed onto a unidimensional classification framework (DTHub, 2020); (d) DT Use Case Framework (National Digital Twin Programme, 2021)

According to Ashby's law of requisite variety (Ashby, 1991), a UCS classification system, if it is to be deemed reliable, adequate and able to generate relevant and manageable search results, must endow users with a variety of search dimensions that are at least equal in number to the variety of key features or aspects that distinguish one DT from one another. Hence, a multi-dimensional or a multi-criteria classification system capable of capturing all the key features and aspects of any GUC or UCS would seem to be a crucial requirement. Moreover, a classification system built upon a well-established framework comprising a set of standard criteria or dimensions could also enable auto-classification of completed UCSs prior to publishing them.

To sum up; in sections 2.1 to 2.3 above, three barriers to the idea of easy, efficient and digital DT knowledge transfer were analysed. Correspondingly, three solutions were suggested, as listed in table 2, providing the basis for the three prongs of the Digital Twin Uses Classification System [DTUCS] proposed in this paper.

Table 2. The three prongs of DTUCS

\begin{tabular}{|l|l|}
\hline DTUCS prong & Aim \\
\hline [A]: Standardize-to-Publish & Help DT stakeholders publish completed UCSs and disseminate knowledge in a common language \\
\hline [B]: Detail-to-Prove & $\begin{array}{l}\text { Prove to DT market the GUC stated is achievable and reproducible through a detailed } \\
\text { documentation of the undertaken UCS }\end{array}$ \\
\hline [C]: Classify-to-Reach & Help asset owners find and retrieve GUCs and/or UCSs relevant to application of interest \\
\hline
\end{tabular}




\section{METHODOLOGY}

\subsection{DTUCS and the three interdependent prongs}

Having established the three-pronged approach to DTUCS, we now argue that these should be developed concurrently rather than sequentially, because all three prongs of DTUCS are equally important and tightly interdependent (Fig. 2).

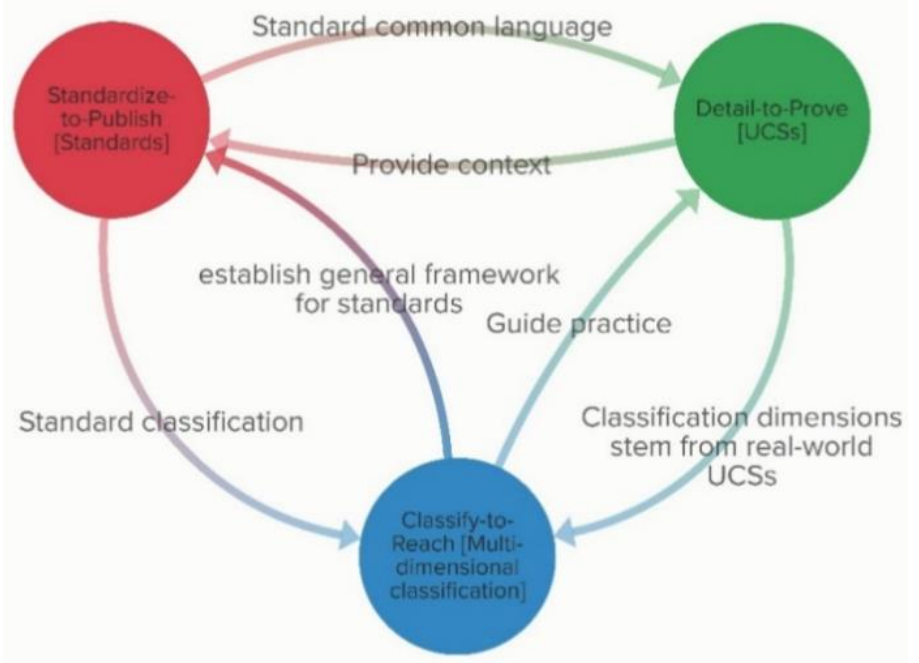

FIG. 2: Interdependencies between three prongs of DTUCS

\subsection{DTUCS development meta-methodology}

The methodology adopted for developing DTUCS, including its three prongs [A: Standardize-to-Publish], [B: Detail-to-Prove] and [C: Classify-to-Reach] (table 2), is divided into four sub-methodologies (Fig. 3): 1) Systematic literature review of DT case studies, proof-of-concepts, pilot projects, and real-world applications in the realm of urban planning and city infrastructure management. Studies selected are used to feed into the second and third sub-methodologies; 2) A simplified ontology development methodology (Noy \& McGuinness, 2001) is followed to develop prong-A (Standardize-to-Publish) capturing all possible 'DT uses' and representing them in a taxonomic form using formulated standard terminology; 3) a framework development methodology (McMeekin et al., 2020) is used to develop prong-C (i.e. Classify-to-Reach) comprising a multi-dimensional GUCs classification framework and; 4) prong-B (i.e. Detail-to-Prove) is developed using the Unified Modelling Language [UML] (Booch, 2005) well-known in the field of software engineering. A detailed explanation of all four parts of DTUCS development meta-methodology will now follow.

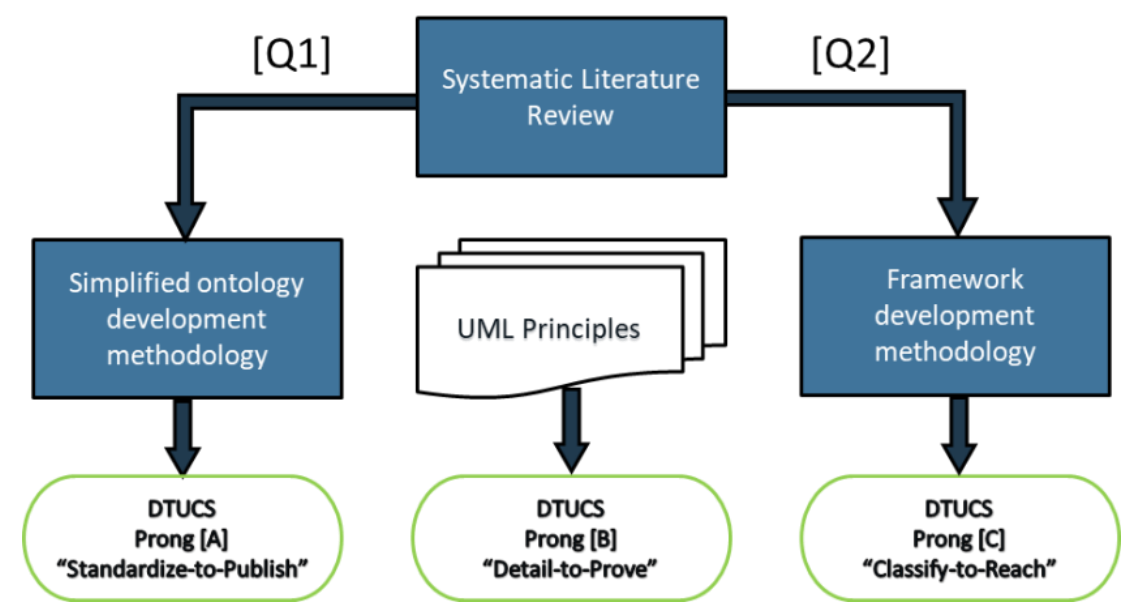

FIG. 3: DTUCS development meta-methodology 


\subsection{Systematic Literature Review}

The systematic literature review started with posing research questions, followed by setting a search strategy and defining inclusion criteria for selection of relevant studies to undergo full text analysis as a part of prongs A and $\mathrm{C}$ development methodologies. Each of these steps, shown in Fig. 4, are thoroughly explained below.

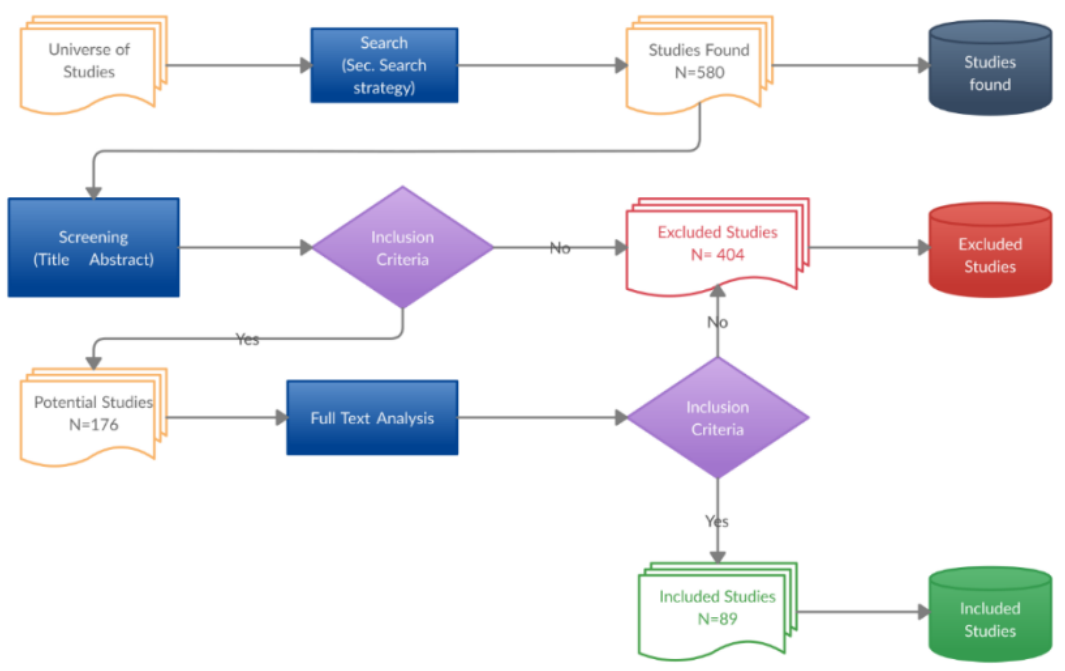

FIG. 4: Systematic literature review flow chart

\subsubsection{Research questions}

Two research questions were posed to guide this systematic literature review; [Q1]: "what are the possible fundamental steps or sequence of actions a DT may perform during its implementation, for it to deliver its highlevel purpose or GUC?” and [Q2]: “what are the key features of a DT differentiating one from another?". Answer to the former question [Q1] informs the simplified ontology development methodology concerned with developing prong-A of DTUCS (i.e. Standardize-to-Publish), while the latter [Q2] feeds into the framework development methodology to create prong-C (i.e. Classify-to-Reach). Both questions are bounded within the fields of urban planning and city infrastructure management.

\subsubsection{Research strategy}

The nature of the research questions raised above provided guidance to designing a bespoke research strategy that is fit for purpose. Both questions are open ones, suggesting exploration of the literature in a broader sense. These types of questions are best addressed by a configurative literature review (Gough et al., 2012, quoted in Dresch et al., 2015), where, in contrast to aggregative reviews, answers to the research questions are sought through qualitative data collected from heterogenous sources, giving rise to newly generated conceptualisations (Fig. 5).

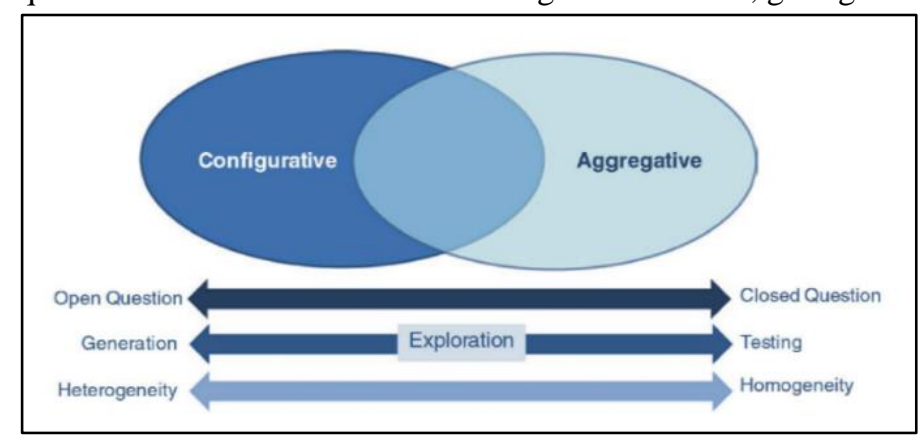

FIG. 5: Configurative vs Aggregative research strategy (Dresch et al., 2015).

Following the configurative research strategy, a variety of relevant keywords were identified and grouped according to the multiple themes intrinsic to the research questions. Smart city initiatives were also considered as they "bore direct resemblance to digital twin conceptualisations" (Nochta et al., 2019, p.14). The search keywords 
included inter alia: 'city'; 'urban'; 'infrastructure'; 'planning'; 'decision making'; digital twin'; 'smart city'; big data'; 'data-driven'; 'analytics'; 'informatics'...etc. Search strings were then developed, iteratively and refined using these keywords joined by the 'AND', 'OR', 'NEAR/\#' boolean operators, to ensure blind spots of every search string were uncovered by other strings. The strings were used to retrieve results from a range of databases and search engines covering both academic as well as grey literature. This was to ensure heterogeneity of studies and to make sure DT solutions and innovative projects led by industry rather than academia were also captured. The search process started in November 2019 and alerts were set at key database search engines to notify the first author of any newly relevant published studies during the course of the study.

\subsubsection{Inclusion criteria}

Studies retrieved were eligible for inclusion if found to satisfy the following a-priori set criteria: (a) they are in the English language; (b) published from 2017 onwards, since the report 'Data for Public Good' released by the National Infrastructure Commission [NIC] in 2017 (National Infrastructure Commission, 2017), is arguably the most influential in the initiation of the DT movement in urban planning and city infrastructure management. In their review, Min et al. (2019) also illustrated the explosion in smart city's research trends that started in 2017; and (c) including either an empirical case study demonstrating a DT in action, or a methodological approach proposing how a DT can be built or a GUC is classified or realized. Titles and abstracts or the introductions of returned documents were screened to identify those deemed potentially eligible and those which can be immediately excluded. Duplicates and full-text dissertations were removed. Potential studies have undergone further testing against the inclusion criteria during full text analysis carried out in developing prongs A and B.

\subsection{DTUCS prong-A development methodology}

Prong-A of DTUCS (i.e. Standardize-to-Publish) is developed using a simplified ontology development methodology. "Ontology, as defined by Guarino, (1998), as 'a hierarchy of concepts related by subsumption relationships...". The method used comprises the following five general steps (Fig. 6).

The first step involves defining the domain and scope of the envisaged standard ontology. Competence questions addressed at this stage included: which domain should be covered by the ontology?; what is the purpose of the ontology for which it should be used for? and what sorts of questions should the knowledge represented in the ontology answer? These questions directly resonate with research questions [Q1] (i.e. "what are the possible fundamental steps or sequence of actions a DT may perform during its implementation, for it to deliver its highlevel purpose or GUC?").

The second step is to ascertain whether any similar ontologies were previously developed within the same domain. Drawing from or adapting to existing and well-established ontologies has several advantages. It saves time and effort consumed in the process of building new ontologies. Building over ontologies or systems existing within the domain helps the domain's practitioners to easily understand the new system; it further ensures consistency with the well-known and widely accepted practices they usually adopt. Furthermore, it forms an extra layer of validation, since existing and well-established ontologies have already gone through several checks and refinement through their applications. One of the identified most similar and relevant previously developed ontologies is a BIM uses classification system (Kreider \& Messner, 2013).

The third step is to enumerate terms. A pool of terms was gradually developed, directly drawing from the studies collected from the systematic literature review, along with support of insights gained from other previously developed systems identified in the second step. After guiding the searching process and the identification of relevant literature, [Q2] (i.e. "what are the possible fundamental steps or sequence of actions a DT may perform during its implementation, for it to deliver its high-level purpose or GUC?") was brought forward onto the qualitative content analysis carried out to enumerate the various 'DT uses' (table 01).

In the fourth step, the listed terms (i.e. DT uses) were then grouped based on mutual and shared properties inherited by those terms and the defined class to which they belong. A mixed method of top-down, bottom-up, middle-out approaches was used, working iteratively between the higher classes and the lowest level terms.

The fifth and final step was mainly concerned with documenting the standard classes and terms in a taxonomic form and providing, in parallel, some instances of the common DT practices to help mapping them onto the system 
and show the standards developed are capable of addressing the competency questions raised in step 1 , and thus add an extra degree of validation.

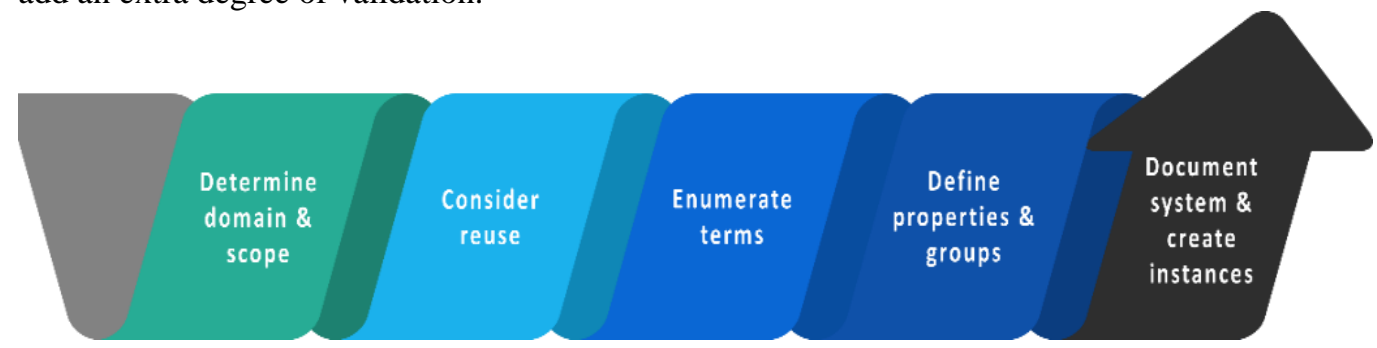

FIG. 6: Five steps of the adopted simplified ontology development methodology,

\subsection{DTUCS prong-B development methodology}

DTUCS's second Prong-B (i.e. Detail-to-Prove) is founded on the Unified Modelling Language [UML], which is a general-purpose modelling language widely used in the field of software engineering to depict use cases of IT applications in a visual form. The advantages of relying on UML as a tool for delivering this prong is three-fold. The transformation of UCSs into a visually perceived form enables a significantly easy and quick way to interpret DT-user interactions. In addition, while the standard format of UML paves the way for auto-detailing and autovisualization of completed UCSs, it also supports the idea of a machine-readable UCSs, hand in hand with the standard terminology of prong-B. Finally, UML is already widely used and accepted as a rigorous language, which spares DTUCS the potential criticisms for relying on some new untested language to present its third prong.

\subsection{DTUCS prong-C development methodology}

A framework development methodology of three stages (McMeekin et al., 2020) was adopted to develop the third and last prong-C of DTUCS (i.e. Classify-to-Reach). First stage consisted of data extraction which included full text analysis of all potential studies retrieved from the systematic literature review, analysed with [Q2] in mind (i.e. "what are the key features of a DT differentiating one from another?"). Second stage consisted of synthesis of involved qualitative content analysis to identify key characteristics of DTs built amongst the reviewed studies. Finally, the third stage was the development of fundamental standard dimensions constituting the DT use case classification system as one integral whole by grouping and amalgamating identified features. The second and third stages were conducted together in an evolving iterative manner.

\section{DTUCS}

\subsection{Prong-A: Standardize-to-Publish}

\subsubsection{Taxonomic structure}

The first prong-A of DTUCS presented in this section incorporates, at its core, a taxonomy of all identified 'DT uses', which are the technical functions or actions executed by DTs in the course of a UCS. DT uses are the standard building blocks upon which a standard common language is founded and subsequently used to document and detail the DT-user interactions in a standard format to facilitate their publishing, sharing of knowledge and avoid miscommunication or confusion amongst DT actors and stakeholders across the DT market. Similar to DT uses in the realm of DTs are the methodologies for modelling and decision-making, as named by Ma et al. (2019), including state-of-the-art tools and techniques implemented within smart city applications. Ma et al. (2019, p.12) state that "many systems use multiple methodologies to build models". This emphasizes the idea of adopting a pluralistic approach in developing models and applications for smart cities. In the same sense, a UCS would normally comprise a unique combination of multiple DT uses.

Fig. 7 illustrates the developed taxonomic form of DT uses. Beneath the GUC, the taxonomy is made up of three distinct hierarchical levels, organized by a parent-child-grandchild relationship. These are respectively: (a) 'Included Uses', containing four high-level cornerstone uses that are, besides rare exceptional cases, included in and executed by almost every DT throughout any UCS (i.e. Mirror, Analyse, Communicate and Control outlined in sections 4.2.2 to 4.2.5); (b) 'Specialized Uses', including special forms of the Included Uses, where each 
specialized use enjoys unique strengths suitable for specific purposes; and (c) "Specialized Sub-Uses" at the lowest hierarchical level of the taxonomy, which further differentiates between variant types within a Specialized Use at the higher level by virtue of very fine inherent variations that distinguish one type from another and thus, enhances the DT's practical adequacy in dealing with alternative contexts and user specifically defined purposes. The following sections give detailed account of each DT use, establishing a standardized terminology that will later aid the realization of the second prong of DTUCS (i.e. Prong-B) - "Detail-to-Prove".

\subsubsection{Mirror}

The idea of a DT is first and foremost concerned with mirroring or duplicating a physical system of interest operating in the real world into a virtual system in the cyber world (Al-Sehrawy \& Kumar, 2021). For this Included Use, the meanings derived or insights gained from the gathered data and their implications on decision making or future interventions have not come to exist yet, rather, the sole objective is to merely sense and collect raw data as produced by the physical system, for a specific application or objective in mind, that is, the GUC. Thus, the captured data must then represent some level of abstraction of reality determined according to the goal in mind. Hence, Mirror is about a mere creation of a model or a shadow of the observed real entity (Kritzinger et al., 2018). Often, this DT use will form the initial step in the roadmap of the actual delivery and realization of a DT GUC. In the context of cities, viewed as a socio-technical system, data constituting a DT may be either primary or secondary. Primary data are exclusive to socio-economic urban layer (see section 4.1.4); they are directly, deliberately and consciously created by humans with an intention to feed the specific DT that tends to leverage this data they create to deliver a purpose for the benefit of the socio-economic layer. On the other hand, secondary data are naturally generated by any of the city layers (see section 4.1.4) as a result of the common everyday urban operations, which happened to be valuable to a DT GUC of interest, and thus, gathered to supply this DT. This DT Included Use (i.e. Mirror) is divided into 4 different Specialized Uses: Capture; Quantify; Monitor; and Qualify as shown in table 3.

\section{Capture}

DTs are used to capture the structure and physical attributes of a real-world system, that is fundamentally, spatialonly data related to geographic location at specified point(s) of time, using variant methods and datasets including but not limited to laser scanners, photogrammetry, morphological structure, demographic, geographic surveys, censuses, spatial information models, infrastructure network topologies or GIS data (Panagoulia, 2017). The common factor within applications of this specialized use is that collected data are mostly historic, static or discrete and akin to straightforward recording of spatial information available in reality. In other words, the capturing DT specialized use supplements a DT with 'static base layer' (ODI, 2020) equivalent to a snapshot of reality at a specific point of time, representing in many cases the 'backbone' of a city structure (Penn \& Al Sayed, 2017). For instance, a study by Boeing (2019) captured big data of urban forms and morphological structures extracted from few popular cities as a part of DT application. Obviously, such type of data is more feasibly captured via offline, rather than online DT (see section 4.1.6 above). For further examples, see Pettit et al. (2018); Lwin et al. (2018); Yabe \& Ukkusuri (2019); and Lu et al. (2017).

\section{Monitor}

By this DT use, measurements and data related to the behaviour or performance of a physical system over time are being dynamically mirrored, by means of spatio-temporal data communication, onto a virtual system whether an online or offline DT. The digital outcome of this DT use is dynamic, reflecting the temporal changes taking place in the twinned real system. Offline DTs are usually more adequate in handling long-term strategic planning of slowly evolving real-world systems, since monitoring may rely on historic records and stored chunks of longitudinal data with temporal information that may resemble throughout its application life, to a great extent, the persistent, slowly changing and almost static reality. For instance, to observe city demographical changes based on stored spatio-temporal data of the last decade. However, in the case of online DTs, monitoring is based on a live influx of data streaming with suitable spatial and temporal resolutions. In short, this DT use facilitates the gathering of longitudinal data related to state, performance and behaviour of dynamic physical systems over time.

Secondary data are commonly retrieved using passive monitoring of data collection while primary data can only be collected using active monitoring (de Castro Neto \& Melo Cartaxo, 2019). Means for passive monitoring may include, environmental sensors, IoT, crowdsensing, social media (Yabe \& Ukkusuri, 2019; Cerrone et al., 2018), cellular phone activity (Kim, 2020) to monitor user activities, computer vision (Ibrahim et al., 2020), cyber- 
physical sensing (Celes et al., 2019), drones (Barmpounakis \& Geroliminis, 2020) or lidar systems (Shirowzhan et al., 2019) to monitor traffic congestions. While, primary data are generated through active monitoring via methods involving the direct and intentional input by humans, like GIS-web tools, collaborative platforms, eparticipation systems or social media.

\section{Quantify}

DTs can be used to count and numerically quantify real-world system's elements, instances or incidents. The measured quantities are defined in terms of the elements or units identified within the physical reality which are based on the determined scale and resolution of the DT. This may include using static, spatial-only data with no temporal dimension, like local pedestrian count data showing pedestrian volumes in relation to land use, to gain insights about the pedestrian socio-spatial structure within a city (Lai \& Kontokosta, 2018); or otherwise, utilizing dynamic data at a defined temporal resolution, such as daily number of commuters. Similar examples may include counting traffic vehicles (Honarvar \& Sami, 2019; Nallaperuma et al., 2019) or train passengers (Wang et al., 2020) over time, whereas the quantities of urban elements taken-off at different points of locations by this DT use - via online or offline DT - if supplemented by temporal dimension, can then support the subsequent inference of spatio-temporal urban patterns.

\section{Qualify}

This DT use is adopted to track the status, condition or mode of a physical system, producing a 'qualified-orunqualified' type of output. An example of a discrete tracking of a physical system's state, may involve checking the operational condition of traffic lights, determining whether it is functioning or not. While a more dynamic case may include the qualification of a bridge safety by the continuous monitoring of its structural health throughout its lifespan (Butler et al. 2019) or detecting whether a trash bin is full or not (Rao et al., 2020; Aktemur et al., 2020; Jadli \& Hain, 2020). Qualification during disasters may include user-tagging to mark whether a citizen is safe or unsafe (White el al., 2021).

Table 3. Included use 'Mirror' and its specialized uses

\begin{tabular}{llll} 
DT Use & Definition & Synonyms \\
\hline $01 \quad$ Mirror & To duplicate a physical system in the real world in the form of a virtual system & $\begin{array}{l}\text { Replicate, twin, model, } \\
\text { shadow, mimic }\end{array}$ \\
\hline 1.1 & Capture & $\begin{array}{l}\text { Express in a digital format within the virtual world the status of a physical collect, scan, survey, } \\
\text { system at a point of time. (Usually, offline DT) }\end{array}$ & digitalize \\
\hline 1.2 & Monitor & $\begin{array}{l}\text { Collecting information related to the performance of a physical system. } \\
\text { (Online or Offline DT) }\end{array}$ & Sense, observe, measure \\
& Quantify & $\begin{array}{l}\text { Measure quantity of a physical system's particulars, instances or incidents. } \\
\text { (Online or Offline DT) }\end{array}$ & Quantify, takeoff, count \\
\hline 1.4 & Qualify & Track the ongoing status of a physical system (Online or Offline DT)
\end{tabular}

\subsubsection{Analyse}

This Included Use is arguably the one through which the greatest value of a DT can be unlocked. It allows for DT owners, users and various stakeholders to leverage the data gathered, through mirroring, in order to create new insightful information that can possibly widen the boundaries of knowledge and deepen the understanding about a physical entity or a complex sociocultural-economic system of systems like a city, thus, providing support in planning and decision making. This may occur through one or more of the following five Specialized Uses: Compute; Mine; Simulate; Predict and Qualitize as shown in Table 4.

\section{Compute}

This specialized use accounts for conventional arithmetical calculations, traditional mathematical operations and relatively simple statistical techniques, like calculating spatial correlation to identify cycling patterns in city (Lieske et al., 2019), or computing indicators and KPIs using formulae comprising a set of independent variables (Anejionu et al., 2019; Kourtit \& Nijkamp, 2018). 


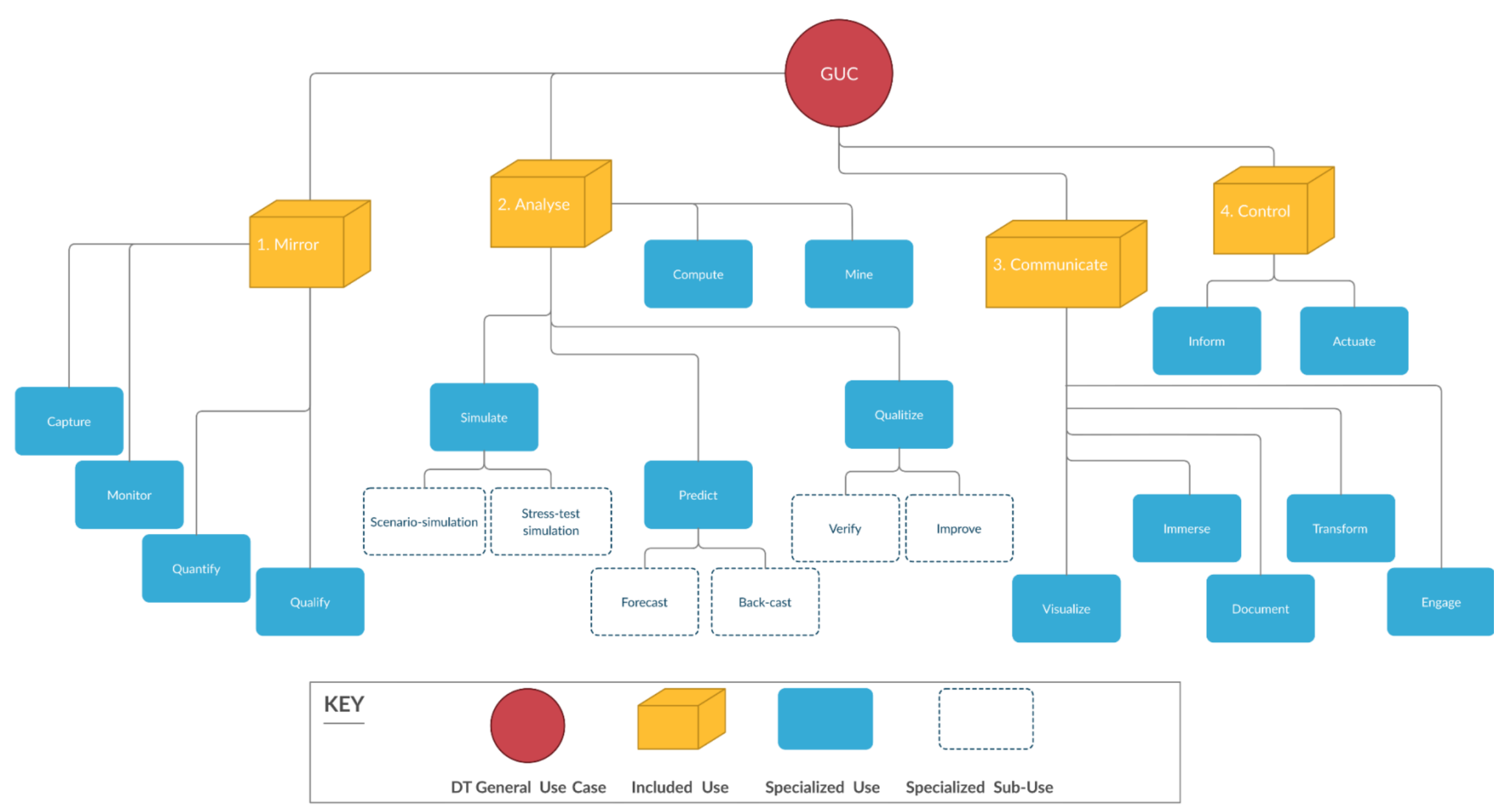

FIG. 7: DTUCS Prong-A taxonomy of DT Uses 
Drawing on Kitchin's (2014) views of data-driven research, this specialized use is the core of what is known as the '4th paradigm of science', heavily relying on Artificial Intelligence $[\mathrm{AI}]$ techniques like machine learning [ML] algorithms, data mining (Bibri \& Krogstie, 2018; Ghaemi et al., 2017) and innovative Big Data Analytics [BDA] to uncover hidden patterns and underlying regularities. The powerful analysis of the enormous amount of big data, can thus offer an unprecedented resolution of world's phenomena. A theoretically validated body of knowledge may still be used to guide this endeavour of data-driven research and discoveries, including the guidance in collecting, managing and processing this big data and interpreting the output in a meaningful way. Some examples include the use of ML techniques to support urban management \& planning to select appropriate locations for public events and optimum land use (Sideris et al., 2019), the deployment of clustering methods to detect distinct urban clusters (Tang et al., 2019), or quantitatively analysing social media data to understand citizen's feelings and activities across different public parks in the city to inform their future development (Plunz et al., 2019).

\section{Simulate}

In this specialized use, computational methods and state-of-the-art digital simulation techniques are used to explore and discover the implications and possible emerging behaviours of a complex web of interconnected variables recognized from the data gathered from the real world. At a lower hierarchical level, two distinct approaches or specialized sub-uses of simulation are identified. The new framework for resilience, recently published by the NIC (National Infrastructure Commission, 2020) clearly differentiates between both.

The first is "scenario-simulation". It mainly relies on raising 'what-if' questions through having predefined scenario(s) prior to simulation, whether derived from a proposed plan or commonly expected risks and hazards. For instance, it may help better understand how infrastructure system of systems may react to expected shocks and stresses. White el al. (2021) carried out flooding and skyline simulations to evaluate their impacts on the city and urban environment. Moreover, Pettit et al. (2018) simulated what-if scenarios of land use futures planning to balance between economic and environmental goals.

On the other hand, the second simulation specialized sub-use is a "stress-test simulation". The idea of this type of simulation is to question the vulnerabilities of the system per se, rather than questioning the impacts of a posited plan or an expected scenario. It is essentially concerned with making use of the virtual system to determine the 'breaking point' of its physical counterpart - akin to 'destructive' testing, the one question sought to be addressed here is: 'what does it take for this or that urban arrangement or infrastructure system to fail or breakdown?'.

\section{Predict}

A DT can be used to predict the future state of a mirrored physical system. This DT specialized use as well can be pursued through two alternative sub-uses: "forecasting" or "backcasting" (Bibri, 2018a; Bibri \& Krogstie, 2020). The former is used to predict the most likely state of a real system in the future, by projecting the known current trends forward over a specified time horizon. Few examples include, using federated learning to predict Covid-19 infection spread and consequent impact on infrastructure services (Pang et al., 2020); using neural networks to predict transportation carbon emissions (Lu et al., 2017); or computing the future levels of accessibility of different neighbourhoods to healthcare facilities across the city, considering the current trends of population increase and demographical changes (Mayaud et al., 2019).

The latter sub-use, backcasting, however, is more concerned with answering, in a prospective manner, the question of 'how' a desirable envisaged future can be attained, rather than the question of 'what' future is likely to occur addressed by forecasting in projective manner. Backcasting, therefore, is typically used as a part of active intervention aiming for a desirable state. In other words, it attempts to find out what scenario or plan of actions is most likely to bring about an a-priori set of aims and objectives.

\section{Qualitize}

This specialized use deals with baseline plans, ideal states, set benchmarks or thresholds, or standards such as building codes and regulations, environmental assessment methods, resilience standards...etc. This use too is further broken down into two sub-uses: "verify" and "improve". For the former, a DT, akin to quality assurance and quality control sort of activities, can be used to verify or validate a plan, design, operational practices or an 
ongoing intervention in terms of compliance and conformance with existing current standards and best practices. For instance, this includes attempts to satisfy Indoor Air Quality (IAQ) standards under different operational circumstances (Rogage et al. 2019). In a similar fashion, Tang et al. (2019) applied clustering techniques to verify the extent to which the ongoing urban development works are conforming with set plans.

On the other hand, that latter sub-use, "improve", is implicitly referred to in the report developed by Arup (2019, p. 39) claiming that in the near future a DT will be "able to inform the future planning and designing of the estate on what has actually been used as opposed to designed based upon standards". This indeed demonstrates a considerable value added by the idea of a DT compared to BIM. While some applications and uses of BIM include the check of design against a set of predefined standards, a DT is capable of going beyond mere validation to, in fact, challenging these standards based on actual real-life operations. In other words, whereas BIM uses information/knowledge contained in standards to create and validate models, a DT is capable of using factual data to rather create this knowledge itself. A clear case of DT-led improvement and enhancement to existing standards is provided by Francisco et al. (2020), where daily energy consumption benchmarks for buildings were computed throughout different seasons. This offers the opportunity for setting benchmarks or standards that are largely inferred from continuously changing real-life practices and operations, rather than theoretical assumptions.

Table 4. Included use 'Analyse', its specialized uses and sub-uses

\begin{tabular}{|c|c|c|c|c|c|}
\hline \multicolumn{4}{|c|}{ DT Use } & Definition & Synonyms \\
\hline \multirow{2}{*}{\multicolumn{2}{|c|}{ Anal }} & \multicolumn{2}{|c|}{ Analyse } & To create new knowledge and provide insights for users and & Examine, manage \\
\hline & & \multicolumn{2}{|c|}{ Compute } & $\begin{array}{l}\text { To perform conventional arithmetical calculations, traditional } \\
\text { mathematical operations and functions and simple statistical } \\
\text { techniques like correlations }\end{array}$ & $\begin{array}{l}\text { Calculate, add, subtract, } \\
\text { multiply, divide }\end{array}$ \\
\hline & 2.2 & \multicolumn{2}{|l|}{ Mine } & $\begin{array}{l}\text { To uncover, identify and recognize the web of interdependencies, } \\
\text { interconnected mechanisms, complex processes, interwoven feedback } \\
\text { loops, masked classes, clusters or typologies, hidden trends and } \\
\text { patterns within the physical system. }\end{array}$ & $\begin{array}{l}\text { Learn, recognize, } \\
\text { identify, detect, AI, } \\
\text { ML, BDA }\end{array}$ \\
\hline & \multirow[t]{3}{*}{2.3} & \multicolumn{2}{|c|}{ Simulate } & \multicolumn{2}{|l|}{$\begin{array}{l}\text { To explore and discover the implications and possible emerging } \\
\text { behaviours of a complex web of interacting set of variables. }\end{array}$} \\
\hline & & 2.3 .1 & Scenario & $\begin{array}{l}\text { To find out the implications, impacts or consequences of } \\
\text { implementing pre-defined scenarios (akin to non-destructive tests) }\end{array}$ & $\begin{array}{l}\text { What-if, evaluate, } \\
\text { assess }\end{array}$ \\
\hline & & 2.3 .2 & Stress-Test & $\begin{array}{l}\text { To identify the scenarios that may lead to failure or breakdown of } \\
\text { physical system (akin to destructive tests) }\end{array}$ & $\begin{array}{l}\text { Test, inspect, } \\
\text { investigate }\end{array}$ \\
\hline & \multirow[t]{3}{*}{2.4} & \multicolumn{2}{|c|}{ Predict } & \multicolumn{2}{|l|}{ Concerned with futures studies } \\
\hline & & 2.4 .1 & Forecast & $\begin{array}{l}\text { to predict the most likely state of a real system in the future, by } \\
\text { projecting the known current trends forward over a specified time } \\
\text { horizon. }\end{array}$ & foresee \\
\hline & & 2.4 .2 & Back-cast & $\begin{array}{l}\text { To question or prove in a prospective manner, how the physical } \\
\text { system is operating towards achieving the pre-set aims and goals. }\end{array}$ & manage, confirm \\
\hline & \multirow[t]{3}{*}{2.5} & \multicolumn{2}{|c|}{ Qualitize } & \multicolumn{2}{|l|}{$\begin{array}{l}\text { Enhance and improve the quality of the outcomes or deliverables } \\
\text { produced by an intervention in real world. }\end{array}$} \\
\hline & & 2.5 .1 & Verify & $\begin{array}{l}\text { Verify conformance and compliance of physical system with } \\
\text { standards, specifications and best practice. }\end{array}$ & $\begin{array}{l}\text { Validate, check, } \\
\text { comply, conform }\end{array}$ \\
\hline & & 2.5 .2 & Improve & $\begin{array}{l}\text { Inform the future updating, modifying or enhancing the current } \\
\text { standards to be in better coherence and harmony with the actual } \\
\text { operational and usage behaviours and patterns. }\end{array}$ & Update, upgrade, revise \\
\hline
\end{tabular}




\subsubsection{Communicate}

A fundamental use of DTs is to communicate the data mirrored via first included use (i.e. Mirror), or the even more insightful information and knowledge created by virtue of the analysis carried out via the second included use (i.e. Analyse) to various stakeholders as necessary according to their interests and the purpose for which the DT is initially deployed. This Included use allows for DT users to interpret, share and exchange such information in order to facilitate better understanding and decision making. Most likely, practicing this DT included use is preceded by - in case of offline DT - or in parallel with - in case of online DT - the implementation of the above two groups of DT Uses: Mirror and Analyse. This group is divided into 5 specialized uses: Visualize; Immerse; Document; Transform and Engage as summarized in table 5.

\section{Visualize}

Visualization, as defined by Garcia and Montané-Jiménez (2020, p.200), "is the process of representing data in a visual and meaningful way to facilitate its understanding." DTs can be used to enhance the exchange and sharing of information through visualization tools and techniques. It helps the emergence and flourishing of diverse perspectives, bringing to the table insights and ideas by various stakeholders who are not necessarily familiar with technical languages, codes and algorithms. Such visualizations can be realized using myriad of tools, like realistic city-scale models, (e.g. city-state of Singapore), walkthroughs, maps for geo-visualization (Anejionu et al. 2019) dashboards (Kourtit \& Nijkamp, 2018), platforms, heatmaps (Barmpounakis \& Geroliminis, 2020), 2D or 3D figures (Nallaperuma et al., 2019; Ghaemi et al., 2017), charts and scatterplots (Garcia \& Montané-Jiménez, 2020) or user-friendly interfaces (Hasegawa et al, 2019). Boeing (2019) visualized the street orientations of various cities via simplistic rose-diagrams. Other studies used geo-visualization techniques to represent patterns and dynamics of traffic vehicles, cyclists and pedestrians across the city.

\section{Immerse}

To further complement the communicational means and collaborative environment within which receivers appreciate and interpret the gathered and analysed data, a DT can enhance real-life perception by virtue of immersive technologies like Virtual Reality [VR], Augmented Reality [AR] and Mixed Reality [MR]. Such techniques, delivering an easy-to-interpret version of information, enable wider participation and involvement and ensure equal levels of understanding among receivers with different social, cultural and language backgrounds. A similar DT use was carried out in Herrenberg in Germany to develop an immersive environment to display simulations of different traffic planning scenarios in a realistic interactive experience (Dembski, Yamu \& Wössner, 2019). While Kent et al. (2019) recommended using VR in city planning, Lock et al. (2019) utilized AR cityscapes to enhance shared understanding of big urban data.

\section{Document}

This specialized use refers to the exporting of collected or analysed data into a representable and most commonly printable form for documentation and further support undertaking studies, preparing reports, or pursuing official organizational approvals. Unlike the outcomes of visualization and immersion, the products of this use are less comprehensible to people who are less technically informed or unfamiliar with technical language. Examples may include DT-based endeavours to produce a business case developed to justify a proposed strategic intervention or a monthly report for operation and maintenance purposes. For example, Afzalan and Sanchez (2017) used a DT to inform the feasibility study of bike-share infrastructure planning. The idea of detailing the UCS sequence of actions and documenting the DT-user interactions as recommended by prong-B of DTUCS, explained in a later section, is another form of documentation.

\section{Transform}

In this use, an eye is kept on the use of DTs at a large scale rather than developing an independent DT for a single asset or organization. This strongly relates to the task of constructing a web of digital twins, as in CDBB's vision of the National Digital Twin (Hetherington \& West, 2020), where for a DT to be connected to other DTs or at least published in a seamlessly usable format, this DT must be transformed from its original form (i.e. application data model) to be compliant with the one predefined common standard language (i.e. integration data model) - also known as Foundation Data Model [FDM] (equivalent to high level core concepts) and Reference Data Library [RDL] (equivalent to sub-classes and vocabularies) - as a part of proper information management. This is to a great extent similar to the general aim of this prong of DTUCS (i.e. prong-A), through which, a DT can rely on 
the standard terminology, developed by prong-A, to transform a UCS into a standard, publishable and possibly machine-readable format.

\section{Engage}

Considering the socio-political system a city is, a novel use offered by the concept of DT in the realm of city infrastructure management and urban planning is people empowerment, civic engagement and encouraging the public to participate in the processes of decision and policy making and planning for the cities of the future, i.e their own future. As Kontokosta $(2017$, p.4) points out, the focus while implementing this DT use, "is not on analytical methods to solve problems", as is the case while adopting specialized uses like Compute or Mine, but "it is to enhance substantive participation by a wider range of stakeholders in typical planning strategies of visioning, goal-setting, and value definition".

So, while other specialized uses (i.e. Compute or Mine) offered various opportunities and methods to quantitatively analyse, inter alia, actively collected primary data, this specialized use (i.e. Engage), however, equip DT users with means to qualitatively interpret the citizens' input, convey their views, voices and feedback, giving rise to a more human- or citizen-centric DT, and a chance to revolutionize city governance and support public consultation and involvement (Nochta el al., 2019). To put it differently, the new generation of IT has also endowed the heterogenous DT toolkit, in addition to 'top-down' techniques, with 'bottom-up' technological methods and tools including, social media, open-source platforms, Internet of People [IoP], gamified engagement tools and others. Hence, unlike passive crowdsensing approaches, for this specialized use, people are neither simply 'monitored' nor 'mirrored' but 'engaged' into the evolvement of real-world interventions (Innovate UK, 2020). In other words, users, for this DT use, are not watched in "a kind of sinister, top-down urban surveillance" (Barns, 2017, p.8) but rather actively involved as contributors to decision making processes. Several studies have demonstrated such approach in practice, in the form of participatory design approach (Panagoulia, 2019) and public participation GIS (Hasegawa et al., 2019) to raise citizen's awareness about the planning of their future city, or Geo-citizen participation and Geo-discussion for urban management and infrastructure planning (Haklay et al., 2019).

There are many examples of this approach, including the initiative of 'FixMyStreet' (Gardner \& Hespanhol, 2018); the public involvement, including the participation of marginalized groups, in the evaluation of city traffic planning scenarios (Dembski, Yamu \& Wössner, 2019); the use of online model to allow for citizens to provide their feedback on mobility development plans and urban policies (White el al., 2021); and the gathering of crowdsourced information via a web-GIS tool to involve citizens in preparation of bike-share feasibility study (Afzalan and Sanchez, 2017).

Table 5. Included use 'Communicate' and its specialized uses

\begin{tabular}{lllll}
\hline \multicolumn{2}{l}{ DT Use } & & Definition & Synonyms \\
\hline 03 & Communicate & To exchange collected and analysed information amongst stakeholders. & interact \\
\hline 3.1 & Visualize & $\begin{array}{l}\text { To form and vision a realistic representation or model of current or } \\
\text { predicted physical system. }\end{array}$ & review, visioning \\
\hline 3.2 & Immerse & $\begin{array}{l}\text { To involve interested stakeholders in real-like experiences using immersive } \\
\text { technologies such as VR, AR and MR. }\end{array}$ & involve \\
\hline 3.3 & Document & $\begin{array}{l}\text { Document and represent gathered and/or analysed data in a professional } \\
\text { manner and technical language, forms or symbols. }\end{array}$ & Present \\
\hline 3.4 & Transform & $\begin{array}{l}\text { To modify, process or standardize information to be published and received } \\
\text { by other DT(s) or other DT users (e.g. a National DT) or overcome } \\
\end{array}$ & interoperability issues & Translate, map \\
\hline 3.5 & Engage & To involve citizens and large groups of people including marginalized & Empower, include
\end{tabular}

\subsubsection{Control}

The Control DT included use encapsulates the uses in which the data captured from a real system and analysed is brought forward to be used to control, regulate or actuate that system. This use explicitly establishes and brings to action the notion of bidirectional communication between physical and virtual systems which underpins the concept of a DT. Table 6 shows the two specialized uses within this included use: "Inform" and "Actuate", resembling the 'passive' and 'active' forms of bidirectional communication, as defined by Al-Sehrawy and Kumar 
(2021); respectively. Analogous to this dichotomy is the typology of 'programmed' and 'non-programmed' types of decisions explicated by Simon (1960). It is worth mentioning that for a DT to Inform or Actuate, it may need to depend on the output produced by the successful execution of other DT included uses (i.e. Mirror, Analyse, Communicate) at first, which is then accumulated in a certain purposeful way and form for the DT to be able to control the problem situation with respect to current circumstances, context and general purpose of the DT as expressed by the GUC.

\section{Inform}

The vast majority of DT applications in the realm of urban management and city-scale planning conclude by enabling this particular specialize use. Whether mirroring a real system, analysing the captured information or communicating the analyses among stakeholders or citizens, they are all meant to finally support and inform the interventions back into the real system at hand. This DT use requires human in the loop of the bidirectional communication to interpret the analysed data and decide or reach a consensus within a collaborative environment on what kind of intervention shall be executed. Generally speaking, it is equally common for both online and offline DTs to inform DT users. It is, in this specialized use, that human act as actuators and decision makers, necessary for the intervention in real world to take place (Ma et al., 2019). This necessity, in fact, reflects the overwhelming complexity and dynamism of the urban environment, as well as our poor understanding of its intrinsically interconnect and changing nature - all requiring collective human judgments for decision making, in other words, to satisfice rather than optimize (Simon, 1960).

\section{Actuate}

Actuation is another specialized means of DT control. While inadequate when it comes to strategic interventions relying on human judgments and collective wisdom, it is indeed more useful and relevant to repetitive type of operational and short-term tasks which occur within relatively closed environments. Such routine tasks are therefore better to be automated in order to achieve higher productivity and bring about more efficient solutions. Actuation does not necessarily represent a smarter approach when compared to informing, however, it is simply more concerned with keeping humans out of the loop of the bidirectional communication between the physical and virtual systems (Akanmu et al., 2013, quoted in Al-Sehrawy \& Kumar, 2021). It is mostly expected for online DTs to enable the efficient execution of this use.

\section{Table 6. Included use 'Control' and its specialized uses}

\begin{tabular}{llll}
\hline DT Use & & Definition & \multicolumn{1}{c}{ Synonyms } \\
\hline 04 & Control & $\begin{array}{l}\text { To leverage the collected and analysed information to intervene back into the } \\
\text { real world to achieve a desirable state. }\end{array}$ & Implement, execute \\
& Inform & $\begin{array}{l}\text { To support human decision making throughout the implementation of } \\
\text { interventions in the real world. }\end{array}$ & Support, aid \\
& Actuate & $\begin{array}{l}\text { Using Cyber Physical Systems and actuators to implement changes to Regulate, manipulate, } \\
\text { physical system. }\end{array}$ & $\begin{array}{l}\text { direct, automate, self- } \\
\text { govern }\end{array}$ \\
\hline 4.2 & & &
\end{tabular}

\subsection{Prong-B: Detail-to-Prove}

\subsubsection{Overview}

Prong-B (i.e. Detail-to-Prove) is concerned with exploiting the Unified Modelling Language [UML] to articulate and depict a UCS. Throughout the years, UML has evolved to become a standard expressive language for specifying and visualizing IT systems and use cases in order to facilitate communication and minimize misunderstanding among stakeholders (for detailed explanation of UML, see Booch, 2005). In the context of DT, prong-B adopts this powerful language to articulate and document, in standard form, the DT-user interactions taking place through a UCS.

At a high level, UML diagrams are built upon four key elements: 'systems', 'actors', 'use cases' and 'relationships'. A 'system' is the artefact we develop, and in our context, this corresponds to the DT mainly described in terms of a GUC. An 'actor' is something or someone using or interacting with the 'system'. For a DT, these could be any of the DT actors or stakeholders (see section 4.3.8 for further details) or the DT itself. A 'use case' represent an action that accomplishes a particular task within the system. For DTUCS prong-B, 'DT uses' (fig.7) are equivalent to 'use cases' in UML. An 'actor', by definition, is using the system for a specific goal. A 'relationship' denotes for this kind of interaction between the 'actor' and the 'system'. 
While prong-A provides the standard terminology for publishing UCSs, Prong-B is where these elements are leveraged, along with the powerful UML language to detail any UCS, demonstrate achievability of a particular GUC and disseminate the 'know-how' across DT market. Fig. 8 shows our suggested process for publishing and subsequent retrieving of UCSs superimposed over the Integration Architecture [IA] of the Information Management Framework [IMF] for the National Digital Twin [NDT] as conceptualized by Hetherington \& West (2020). The valuable contribution arising from this representation is the idea of sharing 'know-how' knowledge, in terms of standardized articulation of DT-user interactions. This is beyond the idea of merely publishing DTs as originally suggested by the IA, whereas a detailed explanation of a how a UCS is carried out would work as evidence of achievability of this particular UCS and thus, provide a real solid proof of how a DT GUC is realized. This is obviously, one can argue, what DT market craves for in order to mature and thrive - exemplars of DT UCSs along with a clear list of DT-User interactions, recorded in standardized terms and form, to enable the transferability and reproducibility of knowledge.

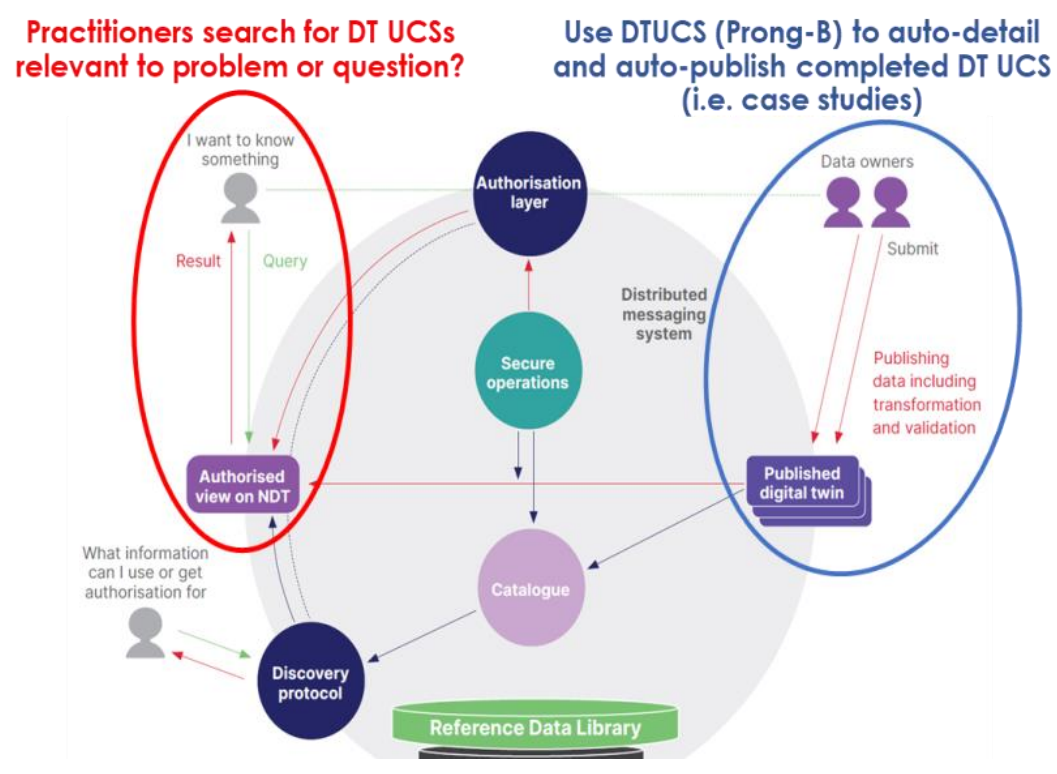

FIG. 8: The auto-publishing of DT Use Case Scenarios in compliance with Integration Architecture of the Information Management Framework as proposed by UK National Digital Twin programme. (Adapted from Hetherington \& West, 2020)

\subsubsection{Prong-B in action: an example from literature}

To further elaborate, a real-world case study (i.e. UCS) is extracted from the literature to help show DTUCS ProngB in action. The selected study, undertaken by Anejionu et al. (2019), proposed a newly developed Spatial Urban Data System [SUDS] to identify neighbourhoods of low liveability across the UK; in their words, they summarize SUDS as:

"a spatial big data infrastructure to support UK-wide analytics of the social and economic aspects of cities and city-regions. It utilises data generated from traditional as well as new and emerging sources of urban data. The SUDS deploys geospatial technology, synthetic small area urban metrics, and cloud computing to enable urban analytics, and geovisualization with the goal of deriving actionable knowledge for better urban management and data-driven urban decision making. At the core of the system is a programme of urban indicators generated by using novel forms of data and urban modelling and simulation programme... [it relies] on the generation and use of regularly updated spatially-activated urban area metrics from real or near-real time data sources, to enhance understanding of intra-city interactions and dynamics. By deploying public transport, labour market accessibility and housing advertisement data in the system, we were able to identify spatial variations of key urban services at intra-city levels as well as social and economically-marginalised output areas in major cities across the UK." (Anejionu et al., 2019, p.456) 
In Fig. 9 below, an excerpt of SUDS's full UCS is depicted in line with the methodological guidelines provided by DTUCS Prong-B. It describes how the Transport Availability Metric [TAM] is computed, based on what sort of data, and finally how it is used along with other computed socio-economic metrics to geo-visualize the areas of low liveability within the UK. It is worth highlighting that the DT actors/stakeholders involved in the UCS are tagged in accordance with the roles defined in DTUCS Prong-C (see section 4.3.8). Moreover, the DT internal uses and actions are put in words of the standard terminology offered by DTUCS Prong-A. As shown, datasets used through the UCS had to be detailed separately in an attached diagram legend.

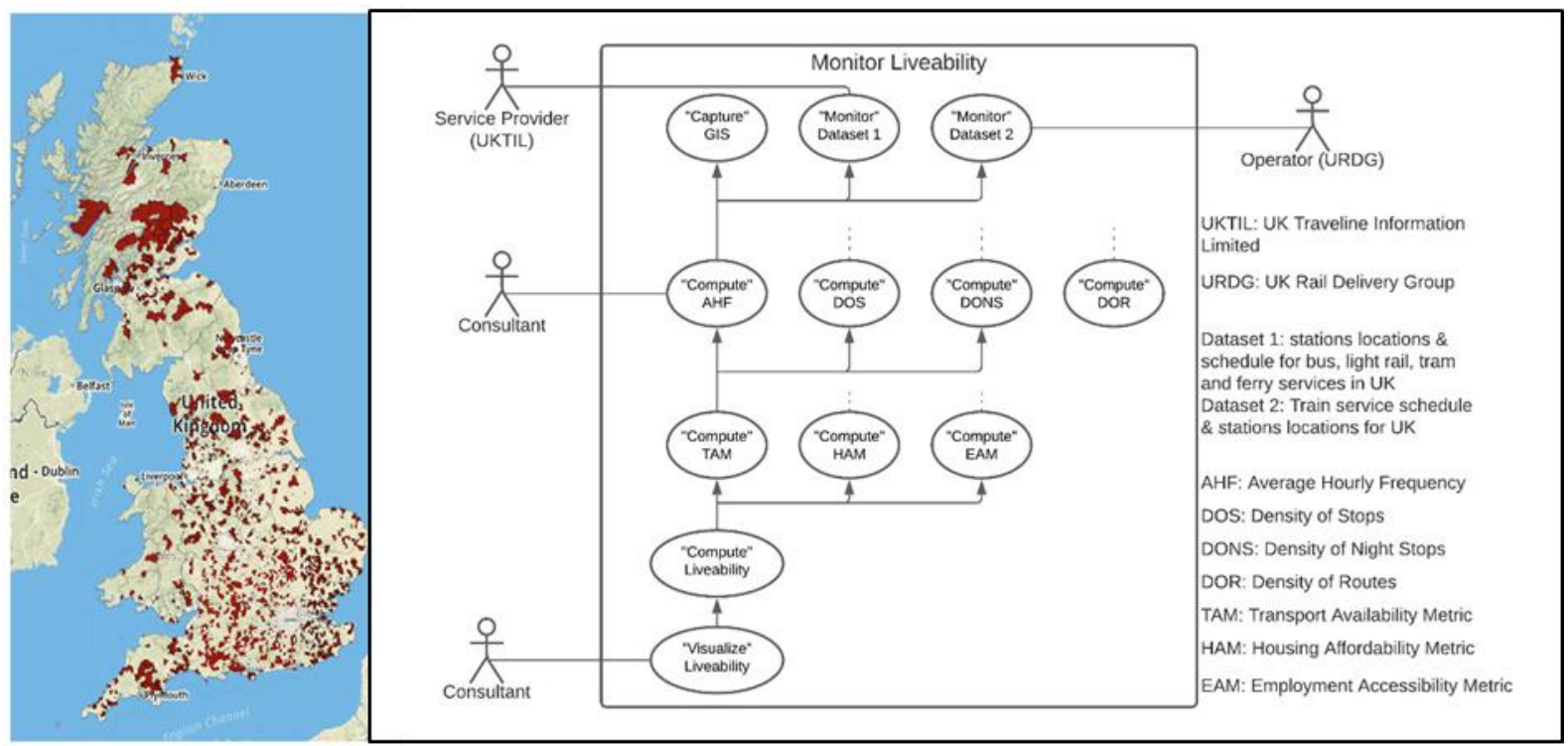

FIG. 9: An example of detailing and modelling a DT Use Case Scenario and DT-user interactions as informed by DTUCS prong-B. (Adapted from Anejionu et al., 2019)

In addition to how prong-B and IMF may complement each other (Fig.8), the former offers potential for further benefits. By virtue of the standard: (a) terms describing the DT uses or actions as developed in prong-A and (b) language used to model DT-user interactions (i.e. UML), Prong-B paves the way for the possibility of automating the task of detailing the UCS and thus, its subsequent publishing. The output of this automated documentation process could then be a machine-readable detailed UCS, that can be easily looked-up for, comprehended and retrieved by other DT owners once it is published across the DT market. This process ultimately works as a catalyst for sharing the explicit 'know-how' describing how a DT has managed to realize a specific GUC, and consequently prove its achievability and support other future DT business cases.

\subsection{Prong-C: Classify-to-Reach}

\subsubsection{Classification system structure}

At the core of Prong-C, fig. 10 illustrates the DT General Use Case [GUC] multi-dimensional classification framework. As Brilakis et al. (2019) pointed out that "digital twins should be driven by purpose [therefore] different use cases will require different update methods and different levels of detail". Correspondingly, the classification framework comprises at its centre the purpose of the particular GUC of interest, ideally articulated in the form of a 'verb' followed by a 'noun' (e.g. optimize traffic), while the seven surrounding dimensions represent the various features altered and refined to suit the central purpose. Based on this, different GUCs can be distinguished and classified. 


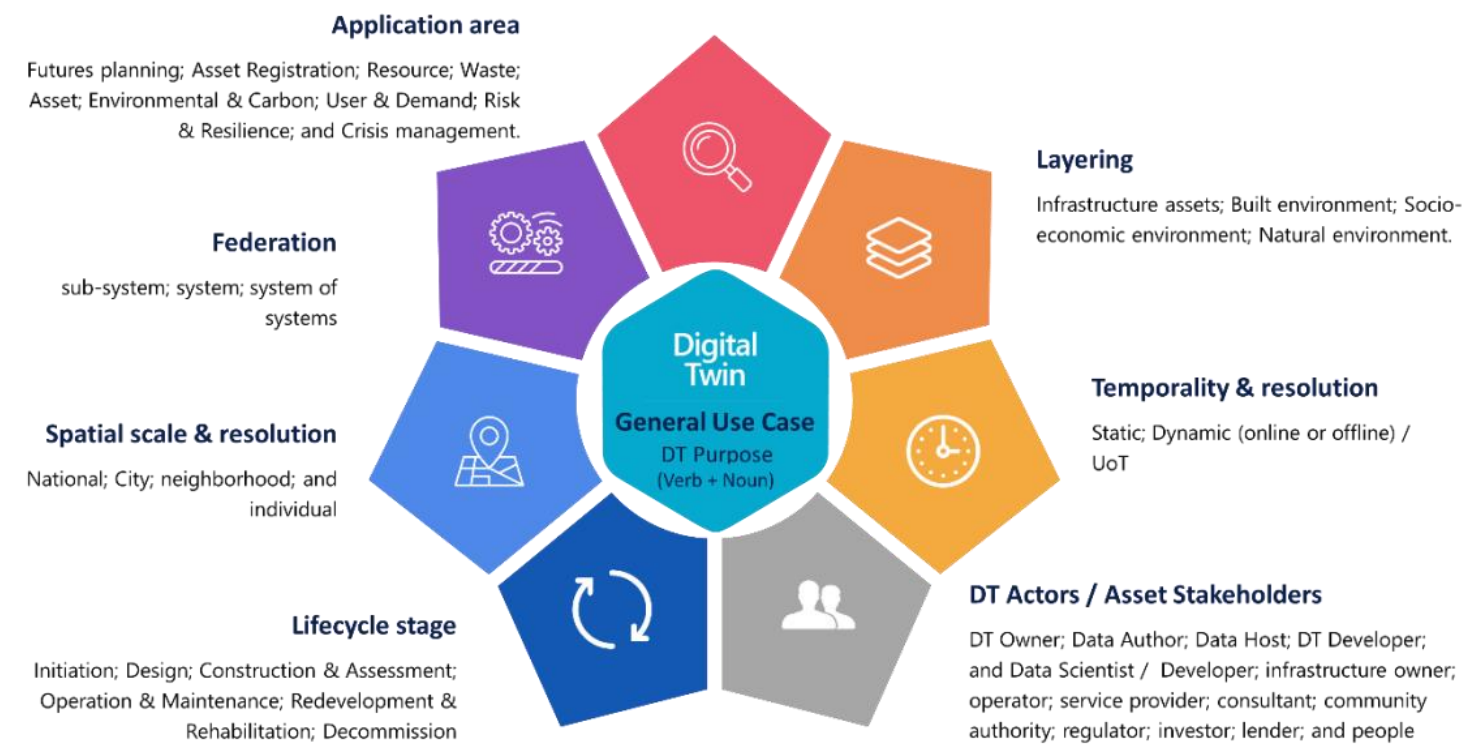

FIG. 10: DT General Use Case multi-dimensional classification framework

\subsubsection{D1: Application areas}

Though still in its nascency for urban planning and city infrastructure management, DT has been proposed to support a diverse range of applications targeting purposes that are worlds apart in terms of scope. Below is an overview of each area of scope, including exemplars drawn from reviewed literature demonstrating ways of how DT tackled each of them.

\section{Futures planning}

concerned with long-term planning, futures studies and strategic forethought. In such manner, Anejionu et al. (2019) deployed a DT to identify urban areas of low liveability in order to inform the planning for future infrastructure development works. Kourtit and Nijkamp (2018) generated urban performance indicators to support strategic decision making. Pettit et al. (2018) developed a DT to help in the allocation of residential land in 2051. Nochta el al. (2020) created a city DT to plan for the expected patterns of private car use in 2031 to ensure sustainable growth.

\section{Asset management}

The scope of work here is more about operating assets and maintaining proper level of service. To this end, Nallaperuma et al. (2019) integrated heterogenous datasets to differentiate recurrent from non-recurrent traffic incidents and simultaneously forecast traffic flow and optimize operation and control decisions. Similarly, Witteborg (2021) explicated how DT may support the smart operation of complex wastewater facilities.

\section{Risk and Resilience management}

DTs have shown a capability to support managing risks in infrastructure domain and help enhance assurance for urban environment. White el al. (2021) used a DT to simulate floods, while Bartos and Kerkez (2020) modeled the urban stormwater network in real-time. Likewise, Wang et al. (2020) exploited the smart rail card ticket data to help protect the safety of urban public transportation. Another study used computer vision to anticipate the risk of heat stress on pedestrians (Mavrokapnidis et al., 2021).

\section{Crisis management}

A DT can aid decision making at times of catastrophes and natural disasters. In the study carried out by White el al. (2021), a DT is used to help identify safest routes and locations for citizens and show those which are mostly affected during flooding. Moreover, citizens themselves can use user-tagging indicating whether they are in need of assistance, thus enabling the DT to identify the most vulnerable locations during the disaster. Lwin et al. (2018) proposed an hourly updated DT showing traffic flow magnitude (i.e. population) and direction in order to enhance emergency preparedness. Yabe and Ukkusuri (2019) worked on predicting the returning behavior of evacuees 
during post-disaster periods. The DT of Pang et al. DT (2020) informs city crisis management decision making amid the spread of a pandemic, that is, Covid-19.

\section{User and Demand management}

DTs are capable of managing the users' behaviors and their usage patterns. Leleux and Webster (2018) presented a smart solution in the form of a gamified engagement platform to offer access to energy information and encourage citizens to alter their energy consumption behavior. Other DT initiatives and studies aimed to change the citizens' lifestyle, travel behavior and their choices of transportation means (Connecting Bristol, 2021; Kirdar $\&$ Ardiç, 2020). In a similar but indirect way, Balletto et al. (2021) attempt to influence public behavior by better utilizing the city's abandoned assets in order to promote walkability as a viable healthy choice, while Orellana and Guerrero (2019) used crowdsourced urban data to better understand the influence of street networks' spatial configuration on the behavioral patterns of cyclists.

\section{Environmental and Carbon management}

A DT promises a variety of solutions when it comes to meeting environmental and carbon targets. Honarvar and Sami (2019) integrated heterogeneous sets of urban data to predict air pollution, mainly with respect to road network traffic dynamics. Another study worked on monitoring and benchmarking the energy consumption of city buildings in real-time which would certainly help realize better environmental performance (Francisco et al., 2020).

\section{Waste management}

At a different level, DTs offer novel approaches to waste management. Several studies have exploited new technologies such as IoT and computer vision to monitor the level of waste in garbage cans, aka smart bins, which can then notify the relevant teams when waste should be collected, and possibly suggest optimum driving routes to be followed during the process of waste collection from a myriad of bins across the city (Rao et al., 2020; Aktemur et al., 2020; Jadli \& Hain, 2020).

\section{Resource management}

This involves identifying the best use of available scarce resources, whether monetary or physical, to realize greatest value. Questions relevant to this area of management can be the sort of questions McHugh and Thakuriah (2018, p.4) raised, like: e.g. where would new infrastructure or transportation service investment deliver greatest benefits? Where is there evidence of dissatisfaction with existing services and resources?". Pertinent use cases may include exploiting DTs to manage human waste, such as sludge used in generating energy. Another possible example is a DT of wind farms, capturing data sensed from wind turbines, analysed with facts about landscape and current wind to optimize configuration of wind turbines to attain higher levels of energy production (GE Renewable Energy, 2021). IET et al. (2019) referred to the value of DT 'what-if' scenario simulations in supporting more sustainable natural resource allocation. IET et al. (2019) emphasized to the value of DT 'in supporting more sustainable natural resource allocation, minimizing environmental degradation and supporting the management of "food-water-energy nexus".

\section{Asset registration}

DT's ability of capturing physical reality is best demonstrated in the idea of asset registration. An exemplar is the 'National Underground Asset Register' project led by the Geospatial Commission in UK. It aims to better map the underground infrastructure assets to deliver strike-less construction and safe working environment. So far, two pilot projects were undertaken; one in London and another in the north east of England (Brammall \& Kessler, 2020).

\subsubsection{D2: Federation}

A DT use case can target an individual infrastructure asset or a group of identical assets, a whole infrastructure system comprising multiple and diverse assets and networks; or ultimately an integrated system of systems [SoS]. In $\mathrm{SoS}$ interdependencies between these infrastructure systems - which have been conventionally seen as independent - be they geospatial, cyber, physical and logical interdependencies (Whyte et al., 2019) - are taken into consideration (ISO, 2020). In the first case, several studies captured infrastructure sub-systems, like basins as a part of the stormwater network (Bartos \& Kerkez, 2020); pedestrian routes, road or rail networks as components 
of the transportation system (Mavrokapnidis et al., 2021; Honarvar \& Sami, 2019; Wang et al., 2020; Barmpounakis \& Geroliminis, 2020; Nallaperuma et al., 2019); or energy consumption of buildings as an element of those connected to the energy grid. In the second case involving full infrastructure systems, Kourtit and Nijkamp (2018) and Anejionu et al. (2019) considered all means of transportation in developing their DTs. Other projects involved multiple distinct infrastructure systems in one DT (Castelli et al., 2019).

A SoS level of federation represents the highest levels of systemic thinking, crossing the organizational boundaries and dissolving the infrastructure sectoral silos. For instance, it was practically adequate for Aktemur et al. (2020) and Jadli and Hain (2020) to consider the functional interdependency between elements of the waste network (i.e. smart bins) and their location with respect to road network in order to identify the best travel route for waste collection. A recent study by the Centre for Digital Built Britain [CDBB] demonstrates an interesting attempt in using a DT to generate new insights concerned with identifying, prioritizing, and managing infrastructure SoS relationships and interdependencies (Whyte et al., 2019).

\subsubsection{D3: Layering}

An important characteristic of many DT use cases is the diffusion across different city layers. The fact that most smart city research and urban DTs are interdisciplinary, involving interdependent urban data and models (Ma et al., 2019), reflects the reality of multiple layers inherent in the fabric of cities and urban environment. Many researchers attempted to disentangle these city layers; White el al. (2021) recognized the four levels: terrain, buildings, infrastructure and mobility, whilst Ibrahim et al. (2020) identified five layers including built environment, humans' interactions, transportation and traffic, infrastructure and natural environment. Similarly, Ma et al. (2019) named five different city domains: transportation, energy, emergency and public safety, social sensing and natural environment. In a review of urban planning needs and urban sensing technologies, Cunningham and Verbraeck (2018) spotted three general conceptual perspectives of the city, including physical and infrastructural, natural resources and political economy. Hence, here we take account of four distinctive city layers: Infrastructure; Built Environment, Socio-economic Environment; and Natural Environment.

Depending on the purpose of a use case, a DT may only need to involve one city layer. Rao et al. (2020) and Aktemur et al. (2020) were only concerned with infrastructure layer (i.e. the layer to which any infrastructure asset belongs) to optimize smart bins and support waste management. More frequently a DT will need to span multiple city layers to meet its objectives. Bartos and Kerkez (2020) included infrastructure along with natural environment to manage urban drainage network, while others considered the interactions between infrastructure and socioeconomic layers (Jadli \& Hain, 2020; Wang et al., 2020; Barmpounakis \& Geroliminis, 2020; Nallaperuma et al., 2019). Some authors alternatively involved varying combinations of three city layers while delivering DT purposes (Anejionu et al., 2019; Honarvar \& Sami, 2019; Kourtit \& Nijkamp, 2018; Francisco et al., 2020; Mavrokapnidis et al., 2021; Barkham et al., 2018; Mayaud et al., 2019), while others included all four as required within some other applications (Pettit et al., 2018). Similarly, Yabe and Ukkusuri (2019) integrated information from heterogeneous sources pertaining to all city layers to predict post-disaster returning behaviour.

\subsubsection{D4: Spatial scale \& resolution}

In pursuit of pre-defined GUC and a-priori DT main purpose, a DT may deliver an output that varies in terms of the spatial scale - commensurate with spatial coverage - and resolution (Gardner \& Hespanhol, 2018; Kontokosta, 2018).These can be at a national, city, neighbourhood or individual levels. Two points should be clarified here, though. First, it is important to distinguish between scale and resolution. For instance, Anejionu et al. (2019) developed a DT that spatially covered the UK (i.e. Nation scale) but supported visualization of livability indicators at a finer, neighbourhood resolution. Second, the finest level, Individual, does not necessarily mean individual human beings, but could be any individual element within a neighbourhood. An individual constituent part of the neighbourhood can be a building, an infrastructural unit, a natural entity, a point of location, a user...etc. The notion of an 'Individual' element here is akin to that of an 'Intelligent Planning Unit' [IPU] as described by Hastak and Koo $(2017$, p.3) to be a "well-defined planning unit that can be initiated to achieve any specific purpose".

Few DTs focus only at a neighbourhood scale with a neighbourhood resolution as well (Panagoulia, 2017). For example, Mavrokapnidis et al. (2021) developed a DT bounded to a specific district to predict the heat exposure on citizens within this district. Nonetheless, various DTs have spatially incorporated full cities, albeit with different levels of resolution. For example, Kourtit and Nijkamp (2018) at best provided no finer resolution than aggregate urban KPIs of the whole city, while Honarvar and Sami (2019) tackled the issue of air quality at every 
neighbourhood within the city. Mayaud et al. (2019) assessed the accessibility of different neighbourhoods to health care facilities across the city; thus, producing a city-scale DT at a neighbourhood resolution. Other highresolution DTs have captured even finer details than city's neighbourhoods. For instance, Barmpounakis and Geroliminis (2020) and Nallaperuma et al. (2019) produced comprehensive information with details about individual vehicles. Some studies introduced DTs to provide information about every single smart bin across the city (Rao et al., 2020; Aktemur et al., 2020; Jadli \& Hain, 2020), while others have rather captured city buildings separately (Francisco et al., 2020) and individual 50m x 50m grids (Kim, 2020). When it comes to national scale, Pang et al. (2020) worked on integrating city DTs across the nation to support better prediction of pandemic infection spreading patterns. One of the best DTs under development at a national scale is the UK's National Digital Twin [NDT] currently pursued by CDBB.

\subsubsection{D5: Temporality \& resolution}

Analogous to spatial scale and resolution, the dynamism and temporality of DT input/output, as well as its temporal resolution, may both change from one use case to another ( $\mathrm{Li}$ et al., 2018). It is crucial to differentiate between three types of DTs with respect to temporality. First is the 'static' DT generating at best static output. Second is the'offline dynamic' DT utilizing historical spatiotemporal data. Third, is the 'online dynamic' DT enjoying a live connection with its physical counterpart. The 'static' DT is based on input that includes no temporal information (e.g. underground asset register). An 'offline dynamic' DT, however, is fed by a chunk of spatiotemporal data, generating an output of a dynamic behaviour. The output, therefore, is quite similar to 4D and 5D simulations, albeit based on real-world data rather than mere theoretical estimations or assumptions (Al-Sehrawy et al., 2019). Notwithstanding its dynamic output, this form of a DT is deemed to be offline - disconnected from the changes taking place in the twinned real physical system and thus, exposed to being outdated by a continuously changing reality. Hence, it can be argued that this type of 'offline dynamic' DTs are more suited to twinning slowly evolving systems, such as city spatial configurations which may take decades to exhibit significant changes worth of capturing. An example is the DT computing urban performance indices and KPIs based on datasets collected from 2012 to 2016 (Kourtit \& Nijkamp, 2018). Similarly, Wang et al. (2020) inferred patterns of railway passengers flow from smart card ticket data containing data of passengers entering and exiting stations in 2017. The third temporality type is 'online dynamic', best suited to twinning real world systems in a constant, rapid or unanticipated change. Online dynamic DTs are viewed by the DT maturity spectrum developed by IET (2019) as a relatively more mature type of DT. This type is tied-up in an enduring connection with the twinned real entity and constantly receiving up-to-date influx of data; thus, can never become obsolete as long as this live digital thread persists. To illustrate, Francisco et al. (2020) relied on IoT technology and smart meters to monitor the energy consumption of buildings in real-time (Rao et al., 2020; Aktemur et al., 2020; Jadli \& Hain, 2020; Nallaperuma et al., 2019).

Dynamic DTs, whether online or offline, must demonstrate a level of temporal resolution, indicating the temporal steps or increments by which the DT input changes. Pertaining to temporal resolution, authors have tried to set some sort of objective levels. For instance, Kontokosta (2018) identified four distinct levels of temporal resolutions (i.e. real-time; daily; annual; and decennial), while acknowledging that the DT output may eventually lie anywhere in between these thresholds. Moreover, it is worth stating that the notion of real-time is a flexible one (Wan, Yang \& Parlikad, 2019). Whereas only the objective in mind driving our intentions to build a DT is responsible for defining the optimum temporal resolution or the frequency by which data generated from a physical system gets transferred to its virtual counterpart. In that sense, the concept of 'real-time' might quite largely overlap, if not match, with that of 'right-time'. As a result, we shall advocate an explicit flexibility in the classification of temporal resolution and set the criteria for measuring the temporal resolution of DTs to be: Unit of Time [UoT].

\subsubsection{D6: Lifecycle Stage}

The output of a DT use case can address more than a one lifecycle phase of the same asset, and perhaps, as AlSehrawy and Kumar (2021) recommend, a vertically integrated DT can connect the asset lifecycle phases in a circular manner. Nonetheless, the majority of DT use cases from the literature review primarily target a specific lifecycle phase even if other phases might find the same generated output beneficial. ISO (2020) developed lifecycle phases for smart communities' infrastructure assets which we shall draw on, including: Initiation; Design; Construction \& Assessment; Operation \& Maintenance; Redevelopment \& Rehabilitation; and Decommission.

\section{Initiation}


DTs in this phase are mostly used to identify and crystalize the needs and motives urging interventions into the urban environment through building infrastructure assets. Several studies involve DT collaborative initiatives like geo-participation and geo-discussion online platforms capturing the city's status quo and fostering public insightful contributions (Haklay et al., 2019; Hasegawa et al., 2019; Nochta el al., 2019). Afzalan and Sanchez (2017) utilized an interactive GIS website interface to allow for interested citizens to suggest their views for bike-share infrastructure planning. (Dembski, Yamu \& Wössner, 2019) engaged diverse groups of citizens to engage in evaluating several traffic development digital scenarios represented using VR technology; thus, pave the way for their intrinsic needs to emerge throughout the process. Kovacs-Györi et al. (2020) used social media data and spatial information to understand citizens' feelings and activities across different locations in the city and have a better grasp of ongoing urban dynamics in order to infer the public needs and preferences.

\section{Design}

At this stage, DTs can help increase the confidence in infrastructure development plans and designs proposed to achieve the public needs, by revealing how new interventions in the urban environment might unfold. White el al. (2021) suggested using sunlight, wind and seismic sensed data to evaluate the consequences of new buildings on the city features, as well as the impact of known city challenges and risks on them. DTs can be used to ensure urban planning decisions have no negative impact on citizens and wider ecosystem (ODI, 2020); to compare between alternative design options, for example to select the optimal allocations of land use in terms of gross value added and home and job creation (Oléron-Evansa \& Salhaba, 2020); or to assess whether new infrastructure developments may hinder current operations (McHugh \& Thakuriah, 2018). In a slightly different approach, Barmpounakis and Geroliminis (2020) used DT to deeply investigate the congestion and critical traffic phenomena, generation knowledge that can significantly support the design of new roads.

\section{Construction}

Relatively fewer studies have investigated the DT use cases during the construction phase. However, an obvious application that promises huge benefits is the underground asset register (Brammall \& Kessler, 2020) with a potential to deliver strike-less and safe working environment. Another valuable use case pertains to the monitoring and control of construction progress. Tang et al. (2019) implemented clustering method to assess the progress of urban development works by evaluating the conformance between the planned urban clusters and the captured actual current state.

\section{Operation and maintenance}

Myriads of DT case studies were advanced to endow asset managers with better grasp of operating urban assets' behavior and state, thus supporting the delivery of well-run operations and maintain satisfactory quality of services. This includes, but is not limited to, the initiative of Wang et al. (2020) to predict short-term rail passengers flow to support operations' decision making or the monitoring of energy consumption within buildings in real-time to aid operational fault-detection (Francisco et al., 2020).

\section{Redevelopment and rehabilitation}

In this phase, insights from DTs are used to reflect on the current state of the urban environment and how, based on the knowledge gained from observing the DT output, this environment and its constituent assets can be further redeveloped and rehabilitated to offer higher level of services and cope with the urban dynamics and changing behavior of social systems. For example, Kourtit and Nijkamp (2018) relied on DT city-scale urban indicators and KPIs to guide setting city redevelopment strategies. Moreover, the continuous monitoring of the heat stress that pedestrians' experiences informed decision makers of redevelopments, including building shades, among other facilities, to overcome this issue (Mavrokapnidis et al., 2021). Another DT approach can be used to direct future redevelopments of road network in such a manner that brings about less air pollution (Honarvar \& Sami, 2019). Again, it is worth re-emphasizing here how the integration of asset lifecycle phases can help the exploitation of knowledge gained through one phase, say operation and maintenance, by other following phases, such as redevelopment and rehabilitation (Al-Sehrawy \& Kumar, 2021).

\section{Decommission}

With the least attention paid by DT researchers and practitioners to this phase, DT continues to promise potential value to be unlocked via real-life applications and case studies. Al-Sehrawy and Kumar (2021) offered a glimpse 
of how DTs can support the knowledge transfer from old to new assets, direct the end-of-life procedures, whether disposal or decommissioning, towards a circular, rather than linear, asset life-cycle and offer more sustainable solutions.

\subsubsection{D7: DT actors \& asset stakeholders}

While most of the DT use cases identified in the literature do not reflect on this dimension, it is expected that any DT use case will have to involve a group of stakeholders. ISO (2020) provides a list of all possible parties that might be interested in the development of smart communities (i.e.: Developer; Infrastructure Owner; Operator; Service Provider; Consultant; Community Authority; Regulator; Investor; Lender; People).

While this list is obviously brough about from an infrastructure asset's point of view, it is useful though to view the acting groups from the DT perspective. Several papers proposed different smart city frameworks and DT development theoretical constructs (see, for example: Kent et al., 2019; Bibri \& Krogstie, 2018; Mamta \& Nagpal, 2018) from which it was possible to deduce some of the key roles, responsibilities and consequently actors in the process of delivering a DT; these may include the following five key DT actors: "DT Owner", simply the client defining the purpose of the DT and pursued outcomes; "Data Author": the creator and issuer of data; "Data Host": offering repositories to store big data, such as cloud storage service provider; "DT Developer": the consultant responsible for building the DT with technical expertise in the field of information systems, to design the DT system architecture, specifications and built-in functions; and "Data Scientist": responsible for data cleaning, standardizing, re-formatting, analyzing, visualizing...etc. in alignment with the DT owner requirements.

A DT use case, in the realm of urban planning and city infrastructure management will include both infrastructure asset stakeholders in addition to DT actors; none of which should be overlooked, and in many cases they may actually overlap. Future officials and city leaders are expected to further enrich their knowledge in data science (Kontokosta, 2017), thus an infrastructure asset operator can be the DT owner of an operation and maintenance DT, while having expert personnel responsible for carrying out the duties normally undertaken by a Data Scientist.

\section{CONCLUSION}

This paper started by critiquing the mainstream approach of enumerating DT use cases and grouping them according to a unidimensional framework. This practice is currently followed by the majority of DT research to help shed light on the potential value of DT and its diverse area of applications, and consequently push towards wider DT adoption. Notwithstanding its generally acknowledged benefits, this approach, we argued, is inadequate in getting the 'buy in' for DT adoption by asset owners. Accordingly, a three-pronged DT Uses Classification System [DTUCS] is proposed and brought about by means of a meta-methodology incorporating distinct submethodologies to develop each prong in the most suitable and adequate manner.

The first prong-A (i.e. Standardize-to-Publish) establishes the standard vocabulary for a common language to be embraced and used across the DT market. At the heart of this prong is a taxonomy of all possible DT uses expressed in a standardized well-defined terminology. The diversity, variety and hierarchical nature of the DT uses shaping the taxonomy endow any DT, typically built upon multiple aggregated DT uses, with sufficient practical versatility necessary to adequately handle the pluralistic reality and complex real-world situations. The idea of standardizing these DT uses paves the way for disseminating the knowledge of how any DT executes the built-in actions or tasks to realize the pre-defined GUC and turning it into a public knowledge available for other practitioners in the DT market with less chances for miscommunication or confusion among stakeholders.

The second prong-B (i.e. Detail-to-prove), however, facilitates the detailing and documentation of a DT Use Case Scenario [UCS]. It depicts the DT-user interactions carried out throughout the journey from the very first input until the realization of the pursued output, using the standard DT uses of Prong-A and the standard well-known modelling language of UML. In other words, while prong-A developed the vocabulary of a standard common language, prong-B puts forward the grammar or the way these terms are constructed and brought together, in line with the rules and principles of UML, to create meaningful illustrations of the DT-user interactions and thus, a comprehensive form of UCS conveying the 'know-how' pertaining to how this DT and its purpose are realized.

Finally, prong-C (i.e. Classify-to-Reach) is supportive in three different ways. Firstly, it provides means based on the constituent dimension or classification criteria, by which asset owners can search for, filter, select and retrieve, from amongst a huge publicly available pool of GUCs, those of relevance and value to a particular context. 
Therefore, helping new DT owners and developers to find out about existing DT best practice with respect to a particular GUC of interest. Secondly, it helps DT practitioners better define and specify the various dimensions or characteristics of a proposed DT, offering them a valuable guiding device prior to and throughout the implementation of a DT project. Thirdly, it is quite possible as well for decision makers to make use of this prong to articulate the DT Owner requirements consistently and exhaustively, enabling effective procurement strategies involving supply and delivery of a complex DT by various multiple parties. In response, prongs A and B, can then collectively, endow DT suppliers at the outset of a project with means to articulate their methodology and plan of work, elaborating on how they intend to satisfy these employer requirements in the form of a detailed baseline sequence of actions subject to evaluation and approval prior to implementation. Indeed, the postulation of all bidding suppliers relying on the same language to propose their DT developing strategy facilitates for fair comparison and consistent evaluation between their different proposed UCSs.

Further implications include the way DTUCS may complement and even upgrade the Information Management Framework [IMF] under development as a part of the UK National Digital Twin [NDT] programme. The IMF is interested in representing real-world entities and their relationships, while DTUCS is concerned with capturing the DT-user interactions which, in fact, occur, evolve, make sense and inherit their content by virtue of these realworld entities and their attributes. Besides, the idea of publishing detailed UCSs rather than mere 'stand-alone' DTs transcends the focus of IMF from the level of information to knowledge, possibly giving rise to what appears to be a Knowledge Management Framework [KMF]. Obviously, this concept of sharing the 'know-how', or knowledge about how a relevant DT use case is being pursued and successfully attained by other DT practitioners is crucial addition to any business case aiming to convince decision makers to adopt a DT. It is, indeed, a solid proof and evidence of achievability, raising the levels of confidence in the DT-based solution suggested.

The concept of standardization inherent in all prongs of DTUCS is potentially an enabler of a machine-readable language and further automation of key processes such as classification, detailing, publishing, searching for and retrieving DT use cases and real-world projects. Machine-readability and automation could unlock great value in the anticipated future, where wide adoption of DT and proliferation of DT use cases require effective dissemination to avoid the risk of loss or underutilisation of know-how.

Future work to further support and validate this framework is by using DTUCS in classifying and detailing DT case studies, whether during project outset or after completion, or to use it in comparative analyses carried out to compare different use cases or alternative implementation strategies of the same use case. Moreover, while DTUCS helps in demonstrating the buildability or achievability of a proposed DT GUC, future research can investigate how other aspects, like usefulness, valuableness, feasibility or effectiveness can be questioned. It is also recommended to generate more evidence of how DTUCS can be merged with the IMF to support establishing a collaborative environment across DT research endeavours and ensure more unified outcomes. At a different level, a significant strengthening of DTUCS may involve the actual transformation of its prongs and standardized language into a tested machine-readable one.

\section{ACKNOWLEDGMENTS}

This is a substantially extended and enhanced version of the paper presented at The 20th International Conference on Construction Applications of Virtual Reality (CONVR 2020): (Al-Sehrawy et al., 2021). We would like to acknowledge the editorial contributions of Professor Nashwan Dawood and Dr. Farzad Rahimian of Teesside University in the publication of this paper.

The authors would like to thank Anna Nunn, the Information Science post-graduate student at the department of Computer and Information Sciences, Northumbria University, for her help in the systematic literature review. 


\section{REFERENCES}

Afzalan, N. and Sanchez, T. (2017). Testing the use of crowdsourced information: Case study of bike-share infrastructure planning in Cincinnati, Ohio. Urban Planning, 2(3), pp.33-44.

Akanmu, A., Anumba, C., \& Messner, J. (2013). Scenarios for cyber-physical systems integration in construction. Journal of Information Technology in Construction (ITcon), 18(12), 240-260.

Aktemur, I., Erensoy, K. and Kocyigit, E. (2020). Optimization of Waste Collection in Smart Cities with the use of Evolutionary Algorithms. In 2020 International Congress on Human-Computer Interaction, Optimization and Robotic Applications (HORA) (pp. 1-8). IEEE.

Al-Sehrawy R., Kumar B. (2021) Digital Twins in Architecture, Engineering, Construction and Operations. A Brief Review and Analysis. In: Toledo Santos E., Scheer S. (eds) Proceedings of the 18th International Conference on Computing in Civil and Building Engineering. ICCCBE 2020. Lecture Notes in Civil Engineering, vol 98. Springer, Cham. https://doi.org/10.1007/978-3-030-51295-8_64

Al-Sehrawy, R., Kumar, B. and Amoudi, O. (2019). Exploitation of BIM in planning and controlling the construction phase on-site carbon emissions: a 6D BIM case study. Innov. Prod. Constr.: Transf. Constr. Emerg. Technol, 279.

Al-Sehrawy R., Kumar B. and Watson R. (2021). Digital Twin Uses Classification System for Urban Planning \& Infrastructure Program Management. In: Dawood N., Rahimian F., Seyedzadeh S., Sheikhkhoshkar M. (eds) Enabling The Development and Implementation of Digital Twins. Proceedings of the 20th International Conference on Construction Applications of Virtual Reality. Teesside University Press, UK.

Anejionu, O.C., Thakuriah, P.V., McHugh, A., Sun, Y., McArthur, D., Mason, P. and Walpole, R. (2019). Spatial urban data system: A cloud-enabled big data infrastructure for social and economic urban analytics. Future Generation Computer Systems, 98, pp.456-473.

Arup (2019). Digital Twins. Towards a meaningful framework. London, UK. Available from: www.arup.com/digitaltwinreport

Ashby, W.R. (1991). Requisite variety and its implications for the control of complex systems. In Facets of systems science (pp. 405-417). Springer, Boston, MA.

Balletto, G., Ladu, M., Milesi, A. and Borruso, G. (2021). A Methodological Approach on Disused Public Properties in the 15-Minute City Perspective. Sustainability, 13(2), p.593.

Barkham, R., Bokhari, S. and Saiz, A. (2018). Urban big data: city management and real estate markets. GovLab Digest: New York, NY, USA.

Barmpounakis, E. and Geroliminis, N. (2020). On the new era of urban traffic monitoring with massive drone data: The pNEUMA large-scale field experiment. Transportation research part C: emerging technologies, 111, pp.50-71.

Barns, S. (2017). FCJ-214 Visions of Urban Informatics: From Proximate Futures to Data-Driven Urbanism. The Fibreculture Journal, (29: Computing the City).

Bartos, M. and Kerkez, B. (2020). pipedream: an interactive digital twin model for urban drainage networks. Accessed in 24 January 2021, https://eartharxiv.org/repository/view/74/

Bibri, S.E. and Krogstie, J. (2018). The big data deluge for transforming the knowledge of smart sustainable cities: A data mining framework for urban analytics. In Proceedings of the 3rd International Conference on Smart City Applications (pp. 1-10).

Bibri, S.E. and Krogstie, J. (2020). The emerging data-driven smart city and its innovative applied solutions for sustainability: the cases of London and Barcelona. Energy Informatics, 3(1), pp.1-42.

Bibri, S.E. (2018). Backcasting in futures studies: a synthesized scholarly and planning approach to strategic smart sustainable city development. European Journal of Futures Research, 6(1), pp.1-27.

Bibri, S.E. (2018). Smart sustainable cities of the future. Springer Berlin Heidelberg. 
Boeing, G. (2019). Spatial information and the legibility of urban form: Big data in urban morphology.

International Journal of Information Management, 56, p.102013.

Booch, G. (2005). The unified modeling language user guide. Pearson Education India.

Brammall, N. and Kessler, H. (2020). An update on the UK government's plans for a national underground asset register. In Proceedings of the Institution of Civil Engineers-Civil Engineering (Vol. 173, No. 2, pp. 5656). Thomas Telford Ltd.

Brilakis, I., Pan, Y., Borrmann, A., Mayer, H., Rhein, F., Vos, C., Pettinato, E. and Wagner, S. (2019). Built Environment Digital Twinning. Technical University of Munich. Accessed in 24 January 2021, https://publications.cms.bgu.tum.de/reports/2020_Brilakis_BuiltEnvDT.pdf

Broo, D.G., Boman, U. and Törngren, M. (2020). Cyber-physical systems research and education in 2030: Scenarios and strategies. Journal of Industrial Information Integration, 21, p.100192.

Castelli, G., Cesta, A., Diez, M., Padula, M., Ravazzani, P., Rinaldi, G., Savazzi, S., Spagnuolo, M., Strambini, L., Tognola, G. and Campana, E.F. (2019), October. Urban intelligence: a modular, fully integrated, and evolving model for cities digital twinning. In 2019 IEEE 16th International Conference on Smart Cities: Improving Quality of Life Using ICT \& IoT and AI (HONET-ICT) (pp. 033-037). IEEE.

Celes, C., Boukerche, A. and Loureiro, A.A. (2019). Crowd management: a new challenge for urban big data analytics. IEEE Communications Magazine, 57(4), pp.20-25.

Cerrone, D., López Baeza, J. and Lehtovuori, P. (2018). Integrative urbanism: using social media to map activity patterns for decision-making assessment. ifkad, pp.1094-1107.

Connecting Bristol. (2021). Connecting Bristol. Creative. Smart. Green. Connected. Connecting Bristol. Accessed in 24 January 2021, http://www.connectingbristol.org/

Cunningham, S.W. and Verbraeck, A. (2018), November. Concepts and constructs of urban sensing. In 2018 IEEE International Conference on Technology Management, Operations and Decisions (ICTMOD) (pp. 184-189). IEEE.

de Castro Neto, M. and de Melo Cartaxo, T. (2019). Smart and collective urban intelligence. T. Rodrigues \& A. Inácio (Eds.), pp.83-94.

Dembski, F., Yamu, C., \& Wössner, U. (2019). Digital Twin, Virtual Reality and Space Syntax: Civic engagement and decision support for smart, sustainable cities. In Proceedings of the 12th International Space Syntax Symposium (pp. 316.1-316.13). Beijing.

Dresch, A., Lacerda, D.P. and Antunes, J.A.V. (2015). Systematic Literature Review. In: Design Science Research. Springer, Cham. https://doi.org/10.1007/978-3-319-07374-3_7

DTHub (Digital Twin Hub). (2020). Centre for Digital Built Britain. Accessed in 24 January 2021, https://digitaltwinhub.co.uk/

Enders, M. R., and Hoßbach, N. (2019). Dimensions of Digital Twin Applications - A Literature Review. In Proceedings of the 25th Americas Conference on Information Systems, Cancun: Mexico, pp. 1-10.

Francisco, A., Mohammadi, N. and Taylor, J.E. (2020). Smart City Digital Twin-Enabled Energy Management: Toward Real-Time Urban Building Energy Benchmarking. Journal of Management in Engineering, 36(2), p.04019045.

García, M.T.C. and Montané-Jiménez, L.G. (2020). Visualization to support decision-making in cities: advances, technology, challenges, and opportunities. In 2020 8th International Conference in Software Engineering Research and Innovation (CONISOFT) (pp. 198-207). IEEE.

Gardner, N. and Hespanhol, L. (2018). SMLXL: Scaling the smart city, from metropolis to individual. City, Culture and Society, 12, pp.54-61.

GE Renewable Energy. (2021). Digital solutions for wind farms. Accesssed in 24 January 2021, https://www.ge.com/renewableenergy/wind-energy/onshore-wind/digital-wind-farm 
Ghaemi, M.S., Agard, B., Trépanier, M. and Partovi Nia, V. (2017). A visual segmentation method for temporal smart card data. Transportmetrica A: Transport Science, 13(5), pp.381-404.

Gough, D., Oliver, S., \& Thomas, J. (2012). An introduction to systematic reviews. London: Sage Publications Ltd.

Guarino, N. (1998). Formal ontology and information systems. In Proceedings of FOIS'98. Trento, Italy: IOS Press, Amsterdam, pp. 3-15.

Haklay, M., Jankowski, P. and Zwoliński, Z. (2018). Selected modern methods and tools for public participation in urban planning-a review. Quaestiones Geographicae, 37(3), pp.127-149.

Hasegawa, Y., Sekimoto, Y., Seto, T., Fukushima, Y. and Maeda, M. (2019). My City Forecast: Urban planning communication tool for citizen with national open data. Comput. Environ. Urban Syst, 77.

Hastak, M. and Koo, C. (2017). Theory of an intelligent planning unit for the complex built environment. Journal of Management in Engineering, 33(3), p.04016046.

Hetherington, J., \& West, M. (2020). The pathway towards an Information Management Framework-A 'Commons' for Digital Built Britain. Centre for Digital Built Britain.

Honarvar, A.R. and Sami, A. (2019). Towards sustainable smart city by particulate matter prediction using urban big data, excluding expensive air pollution infrastructures. Big data research, 17, pp.56-65.

Ibrahim, M.R., Haworth, J. and Cheng, T. (2020). Understanding cities with machine eyes: A review of deep computer vision in urban analytics. Cities, 96, p.102481.

IET (The Institution of Engineering and Technology). (2019). Digital twins for the built environment. An introduction to the opportunities, benefits, challenges and risks. Accessed in 24 Januray 2021, https://www.theiet.org/media/4715/leaflet-digital-twins-for-the-built-environment-iet-atkins.pdf

Innovate UK: Technology Strategy Board, Glasgow City Council. (2020). Future City Glasgow. Accessed in 24 January 2021, https://futurecity.glasgow.gov.uk/

ISO. (2020). 37155: 2020 Framework for integration and operation of smart community infrastructures. Part 1: Recommendations for considering opportunities and challenges from interactions in smart community infrastructures from relevant aspects through the life cycle. The British Standarts Institution.

Jadli, A. and Hain, M. (2020). Toward a Deep Smart Waste Management System based on Pattern Recognition and Transfer learning. In 2020 3rd International Conference on Advanced Communication Technologies and Networking (CommNet) (pp. 1-5). IEEE.

Kent, L., Snider, C. and Hicks, B. (2019). Early stage digital-physical twinning to engage citizens with city planning and design. In 2019 IEEE Conference on Virtual Reality and 3D User Interfaces (VR) (pp. 1014-1015). IEEE.

Kim, Y.L. (2020). Data-driven approach to characterize urban vitality: how spatiotemporal context dynamically defines Seoul's nighttime. International Journal of Geographical Information Science, 34(6), pp.12351256.

Kirdar, G. and Ardiç, S.I. (2020). A design proposal of integrated smart mobility application for travel behavior change towards sustainable mobility. Civil Engineering and Architecture, 8(5).

Kitchin, R. (2014). Big Data, new epistemologies and paradigm shifts. Big data \& society, 1(1), 2053951714528481.

Kontokosta, C.E. (2017). Urban informatics for social good: definitions, tensions, and challenges. In Proceedings of the 2nd International Workshop on Science of Smart City Operations and Platforms Engineering (pp. 52-56).

Kontokosta, C.E. (2018). Urban informatics in the science and practice of planning. Journal of Planning Education and Research, p.0739456X18793716. 
Kourtit, K. and Nijkamp, P. (2018). Big data dashboards as smart decision support tools for i-cities-An experiment on Stockholm. Land use policy, 71, pp.24-35.

Kovacs-Györi, A., Ristea, A., Havas, C., Mehaffy, M., Hochmair, H.H., Resch, B., Juhasz, L., Lehner, A., Ramasubramanian, L. and Blaschke, T. (2020). Opportunities and Challenges of Geospatial Analysis for Promoting Urban Livability in the Era of Big Data and Machine Learning. ISPRS International Journal of Geo-Information, 9(12), p.752.

Kritzinger, W., Karner, M., Traar, G., Henjes, J., \& Sihn, W. (2018). Digital Twin in manufacturing: A categorical literature review and classification. IFAC-PapersOnLine, 51(11), 1016-1022. https://doi.org/10.1016/j.ifacol.2018.08.474

Lai, Y. and Kontokosta, C.E. (2018). Quantifying place: Analyzing the drivers of pedestrian activity in dense urban environments. Landscape and Urban Planning, 180, pp.166-178.

Leleux, C. and Webster, W. (2018). Delivering smart governance in a future city: The case of Glasgow. Media and Communication, 6(4), pp.163-174.

Li, M., Ye, X., Zhang, S., Tang, X. and Shen, Z. (2018). A framework of comparative urban trajectory analysis. Environment and Planning B: Urban Analytics and City Science, 45(3), pp.489-507.

Lieske, S.N., Leao, S.Z., Conrow, L. and Pettit, C. (2019). Assessing geographical representativeness of crowdsourced urban mobility data: An empirical investigation of Australian bicycling. Environment and Planning B: Urban Analytics and City Science, p.2399808319894334.

Lock, O., Bednarz, T. and Pettit, C. (2019). HoloCity-exploring the use of augmented reality cityscapes for collaborative understanding of high-volume urban sensor data. In The 17th International Conference on Virtual-Reality Continuum and its Applications in Industry (pp. 1-2).

Lu, X., Ota, K., Dong, M., Yu, C. and Jin, H. (2017). Predicting transportation carbon emission with urban big data. IEEE Transactions on Sustainable Computing, 2(4), pp.333-344.

Lwin, K.K., Sekimoto, Y. and Takeuchi, W. (2018). Estimation of Hourly Link Population and Flow Directions from Mobile CDR. ISPRS International Journal of Geo-Information, 7(11), p.449.

Ma, M., Preum, S.M., Ahmed, M.Y., Tärneberg, W., Hendawi, A. and Stankovic, J.A. (2019). Data sets, modeling, and decision making in smart cities: A survey. ACM Transactions on Cyber-Physical Systems, 4(2), pp.1-28.

Mamta and Nagpal, C.K. (2018). Urban Computing: Key Challenges and Issues of Traffic Management System. Int. J. Comput. Appl, 179, pp.18-21.

Mavrokapnidis, D., Mohammadi, N. and Taylor, J. (2021). Community Dynamics in Smart City Digital Twins: A Computer Vision-based Approach for Monitoring and Forecasting Collective Urban Hazard Exposure. In Proceedings of the 54th Hawaii International Conference on System Sciences (p. 1810).

Mayaud, J.R., Anderson, S., Tran, M. and Radić, V. (2019). Insights from self-organizing maps for predicting accessibility demand for healthcare infrastructure. Urban Science, 3(1), p.33.

McHugh, A. and Thakuriah, V. (2018). Developing smart statistics for urban mobility: challenges and opportunities. Accessed in 24 January 2021, https://dgins2018.statisticsevents.ro/wpcontent/uploads/2018/10/23-Developing-smart-statistics-for-urban-mobility.pdf

McMeekin, N., Wu, O., Germeni, E. and Briggs, A. (2020). How methodological frameworks are being developed: evidence from a scoping review. BMC medical research methodology, 20(1), pp.1-9.

Min, K., Yoon, M. and Furuya, K. (2019). A Comparison of a smart city's trends in urban planning before and after 2016 through keyword network analysis. Sustainability, 11(11), p.3155.

Nallaperuma, D., Nawaratne, R., Bandaragoda, T., Adikari, A., Nguyen, S., Kempitiya, T., De Silva, D., Alahakoon, D. and Pothuhera, D. (2019). Online incremental machine learning platform for big datadriven smart traffic management. IEEE Transactions on Intelligent Transportation Systems, 20(12), pp.4679-4690. 
National Digital Twin programme (2021). Digital twin toolkit. DT Hub. https://digitaltwinhub.co.uk/files/file/62digital-twin-toolkit/

National Infrastructure Commission. (2017). Data for the public good, National Infrastructure Commission report, London, December 14, p. 76, Accessed in 24 January 2021, www.nic.org.uk/publications/datapublic-good/

National Infrastructure Commission. (2020). Anticipate, react, recover. Resilient infrastructure systems. National Infrastructure Commission.

Nochta, T., Badstuber, N. and Wahby, N. (2019). On the Governance of City Digital Twins-Insights from the Cambridge Case Study. Centre for Digital Built Britain. DOI: https://doi.org/10.17863/CAM.41083

Nochta, T., Parlikad, A., Schooling, J., Badstuber, N. and Wahby, N. (2019). The local governance of digital technology-Implications for the city-scale digital twin. Centre for Digital Built Britain

Nochta, T., Wan, L., Schooling, J.M. and Parlikad, A.K. (2020). A Socio-Technical Perspective on Urban Analytics: The Case of City-Scale Digital Twins. Journal of Urban Technology, pp.1-25.

Noy, N. F., \& McGuinness, D. L. (2001). Ontology Development 101: a guide to creating your first ontology. Accessed in 24 January 2021, http://www-ksl.stanford.edu/people/dlm/papers/ontology-tutorial-noymcguinness.pdf.

ODI (Open Data Institute). (2020). Case study: Creating a digital version of a city. Accessed in 24 January 2021, https://theodi.org/article/case-study-creating-a-digital-version-of-a-city/

Oléron-Evansa, T.P. and Salhaba, M. (2020). Optimal Land Use Allocation for the Heathrow Opportunity Area Using Multi-Objective Linear Programming. UCL Centre for Advanced Spatial Analysis, paper219.

Orellana, D. and Guerrero, M.L. (2019). Exploring the influence of road network structure on the spatial behaviour of cyclists using crowdsourced data. Environment and Planning B: Urban Analytics and City Science, 46(7), pp.1314-1330.

Panagoulia, E. (2017). Open Data and Human-Based Outsourcing Neighborhood Rating: A Case Study for San Francisco Bay Area Gentrification Rate. In International Conference on Computers in Urban Planning and Urban Management (pp. 317-335). Springer, Cham.

Panagoulia, E. (2019). Human-Centered Approaches in Urban Analytics and Placemaking. In Sustainability in Urban Planning and Design. IntechOpen.

Pang, J., Li, J., Xie, Z., Huang, Y. and Cai, Z. (2020). Collaborative City Digital Twin For Covid-19 Pandemic: A Federated Learning Solution. arXiv preprint arXiv:2011.02883.

Penn, A. and Al Sayed, K. (2017). Spatial information models as the backbone of smart infrastructure. Environment and Planning B: Urban Analytics and City Science, 44(2), pp.197-203.

Pettit, C., Bakelmun, A., Lieske, S.N., Glackin, S., Thomson, G., Shearer, H., Dia, H. and Newman, P. (2018). Planning support systems for smart cities. City, culture and society, 12, pp.13-24.

Plunz, R.A., Zhou, Y., Vintimilla, M.I.C., Mckeown, K., Yu, T., Uguccioni, L. and Sutto, M.P. (2019). Twitter sentiment in New York City parks as measure of well-being. Landscape and urban planning, 189, pp.235246.

Rao, P.V., Azeez, P.M.A., Peri, S.S., Kumar, V., Devi, R.S., Rengarajan, A., Thenmozhi, K. and Praveenkumar, P. (2020). IoT based Waste Management for Smart Cities. In 2020 International Conference on Computer Communication and Informatics (ICCCI) (pp. 1-5). IEEE.

Rogage, K., Clear, A., Alwan, Z., Lawrence, T., \& Kelly, G. (2019). Assessing building performance in residential buildings using BIM and sensor data. International Journal of Building Pathology and Adaptation. 
Shirowzhan, S., Trinder, J. and Osmond, P. (2019). New metrics for spatial and temporal 3D Urban form sustainability assessment using time series lidar point clouds and advanced GIS techniques. In Sustainability in Urban Planning and Design. IntechOpen.

Sideris, N., Bardis, G., Voulodimos, A., Miaoulis, G. and Ghazanfarpour, D. (2019). Using random forests on real-world city data for urban planning in a visual semantic decision support system. Sensors, 19(10), p.2266.

Simon, H. A. (1960). The new science of management decision.

Tang, L., Gao, J., Ren, C., Zhang, X., Yang, X. and Kan, Z. (2019). Detecting and evaluating urban clusters with spatiotemporal big data. Sensors, 19(3), p.461.

Wan, L., Yang, T., \& Parlikad, A. (2019). City-Level Digital Twin Experiment for Exploring the Impacts of Digital Transformation on Journeys to Work in the Cam-bridge Sub-region. (CDBB_REP_34) https://doi.org/10.17863/CAM.43317

Wang, Y., Zhang, W., Zhang, F., Yin, L., Zhang, J., Tian, C. and Jiang, W. (2020). Analysis of subway passenger flow based on smart card data. In 2020 6th International Conference on Big Data Computing and Communications (BIGCOM) (pp. 198-202). IEEE.

White, G., Zink, A., Codecá, L. and Clarke, S. (2021). A digital twin smart city for citizen feedback. Cities, 110, p.103064.

Whyte, J., Chen, L., Gamble, C., Genes, C., Pierce, K., Fitzgerald, J., Coca, D., Mayfield, M., Babovic, F., Pedro, A., Shah, N. (2019). Analysing Systems Interdependencies Using a Digital Twin, 2018/19 General Project funded by CDBB, Final Report.

Witteborg, A. (2021). Digital twins for wastewater infrastructure. Royal HaskoningDHV Digital. Accessed in 24 January 2021, https://global.royalhaskoningdhv.com/digital/blogs-and-news/publications/digital-twinsfor-wastewater-infrastructure

Xie, Y., Gupta, J., Li, Y. and Shekhar, S. (2018). Transforming smart cities with spatial computing. In 2018 IEEE International Smart Cities Conference (ISC2) (pp. 1-9). IEEE.

Yabe, T. and Ukkusuri, S.V. (2019). Integrating information from heterogeneous networks on social media to predict post-disaster returning behavior. Journal of Computational Science, 32, pp.12-20.

Ye, C., Butler, L., Bartek, C., Iangurazov, M., Lu, Q., Gregory, A., Girolami, M. \& Middleton, C. (2019). A Digital Twin of Bridges for Structural Health Monitoring. In 12th International Workshop on Structural Health Monitoring 2019. Stanford University. 